This item was submitted to Loughborough's Research Repository by the author.

Items in Figshare are protected by copyright, with all rights reserved, unless otherwise indicated.

\title{
On the economic fundamentals behind the dynamic equicorrelations among asset classes: Global evidence from equities, real estate, and commodities
}

\section{PLEASE CITE THE PUBLISHED VERSION}

https://doi.org/10.1016/j.intfin.2021.101292

\section{PUBLISHER}

Elsevier

VERSION

AM (Accepted Manuscript)

\section{PUBLISHER STATEMENT}

This paper was accepted for publication in the journal Journal of International Financial Markets, Institutions and Money and the definitive published version is available at https://doi.org/10.1016/j.intfin.2021.101292

\section{LICENCE}

CC BY-NC-ND 4.0

\section{REPOSITORY RECORD}

Karanasos, Menelaos, and Stavroula Yfanti. 2021. "On the Economic Fundamentals Behind the Dynamic Equicorrelations Among Asset Classes: Global Evidence from Equities, Real Estate, and Commodities". Loughborough University. https://hdl.handle.net/2134/16809952.v1. 


\title{
On the Economic fundamentals behind the Dynamic
}

\section{Equicorrelations among Asset classes: Global evidence from}

Equities, Real estate, and Commodities.

\author{
M. Karanasos ${ }^{\dagger}$, S. Yfanti $i^{\ddagger, *}$ \\ ${ }^{\dagger}$ Brunel University London, UK; ${ }^{\ddagger}$ Loughborough University, UK
}

January 2021

\begin{abstract}
We reveal the macroeconomic determinants of the dynamic correlations between three global asset markets: equities, real estate, and commodities. Conditional equicorrelations, computed by the GJR-GARCH-DECO model, are explained by the macro-financial proxies of economic policy and financial uncertainty, credit conditions, economic activity, business and consumer confidence, and geopolitical risk. Our results suggest that elevated cross-asset correlations are associated with higher uncertainty, tighter credit conditions, and lower geopolitical risk, while lower correlations are related to stronger economic activity, business, and consumer confidence. We further focus on economic policy uncertainty (EPU) as a potent catalyst of the asset markets integration process and conclude that EPU magnifies all macro-effects across all correlations. Lastly, we investigate the global financial crisis effect on the time-varying impact of the correlations' macro-drivers. The crisis structural break amplifies the influence that all determinants exert on the evolution of correlations apart from the geopolitical risk upshot, which is alleviated after the crisis advent.
\end{abstract}

Keywords: commodities, cross-asset dynamic equicorrelations, economic policy uncertainty, global equities, macro-financial linkages, REITs.

JEL classification: C32, C58, D80, E44, G01, G15, Q02, R33

*Address for correspondence: Stavroula Yfanti, School of Business and Economics, Loughborough University, Epinal Way, Loughborough, Leicestershire, LE11 3TU, UK; email: stavyfan@gmail.com, tel: +44 (0)1509 227091. 


\section{Introduction}

The study of dynamic cross-asset linkages concerns a pivotal part of the empirical finance literature with crucial implications for portfolio selection and risk management practices. Asset and risk managers focus on returns correlations among different investment areas to achieve portfolio diversification benefits and hedging effectiveness. The dynamic nature of returns and volatilities co-movement is thoroughly explored through the multivariate GARCH framework. However, the literature on the common economic forces that drive the time-varying pattern of the evolution of conditional correlations among different asset classes remains relatively silent. The macroeconomic determinants of linkages between financial markets for different asset classes are of utmost importance also for policymakers. Increased correlations in turbulent times (times of excess volatility or dramatic price drops) often lead to financial contagion and systemic risk build-up, which regulators should proactively assess and mitigate. Hence, understanding the common economic fundamentals that lie at the core of markets' interdependence in the financial system contributes to the necessary tools for prudential regulation, oversight, and effective policy responses.

Against this backdrop, the primary objective of the present study is to define the macroeconomic determinants of the dynamic correlations between three asset markets: equities, real estate, and commodities. We focus on the particular risky assets since they are most frequently included in multi-asset portfolios and represent a major part of the financial markets investment universe. We do not explore correlations with bonds, which are often the safe-havens in portfolio diversification, because bond yields and volatilities are used, here, as proxies for the credit channel in the macro-determinants we investigate. We apply the Dynamic Equicorrelations (DECO) model of Engle and Kelly (2012) to estimate the dynamic correlations of three global benchmark indices: the MSCI World Equities (MXWO) index, the Dow Jones Real Estate Investment Trusts (REIT) index, and the Standard \& Poor's Global Commodity (GSCI) index. These three indices measure the performance of each market globally and are widely used as overall benchmarks for investing in equity, real estate, and commodity markets.

All three investment areas play a vital role in the real economy apart from being considered as attractive assets. Equities incorporate the firm valuations as a result of their operations' contribution to the aggregate real economy. Real estate is a major lever of economic growth given its role as a significant enabler of economic activity, and commodities represent the main resources of production. Therefore, the correlation trajectory of the three markets should be explained by factors related to the real economy, besides the well-established literature that provides sound evidence of the cross-asset markets integration

as the new legacy in financial investments. The inter-asset correlations and volatility spillovers have been widely covered by existing research through the financialization hypothesis for the commodity markets. Eminent scholars have shown the significant co-movement of commodities with conventional 
financial assets (e.g. equities) as a result of the huge increase of capital flows in commodity investment positions (see, for example, Silvennoinen and Thorp, 2013, for further discussion and literature on the correlation dynamics based on the financialization hypothesis and cross-asset markets integration). Case et al. (2012), among others, illustrate the importance of the REIT-stocks correlation in the Markowitz mean-variance framework. Lastly, several studies have also demonstrated that all these financial markets' co-movements respond to macroeconomic news arrival (see, for example, Brenner et al., 2009, who find that asset interactions are significantly driven by macro-information releases).

Hence, the time-varying correlations between stocks, securitized real estate, and commodities are further analyzed to answer our main question: What drives their evolution? We reveal the common economic mechanisms behind the cross-asset co-movement on both daily and monthly frequency. Our empirical evidence points to significant effects on correlations from six macro-financial factors: i) policy and ii) financial uncertainty, iii) credit conditions, iv) economic activity, v) investors' sentiment (business and consumer), and vi) geopolitical risk. We further investigate the policy uncertainty impact on the influence that each of the remaining five macro-proxies exerts on dynamic correlations. Finally, we apply the structural breaks detected on the correlations time series to study the global financial crisis ramifications on the macro-effects. In this vein, our main finding underscores the importance of policy uncertainty, which exacerbates all cross-asset correlations and partly drives the other five macro-effects with an inflating impact likewise. Moreover, we estimate a significant negative signed effect for economic activity proxies, investor sentiment, and geopolitical risk, while heightened financial uncertainty and tighter credit conditions are positively related to correlations, similar to the influence of policy uncertainty. From an economic point of view, the macro-effects on cross-asset correlations observed through the DECO framework confirm prior studies (see, for example, Fang et al., 2018b, Yang et al., 2012) on the upward correlation trajectory during economic downturns. All forces associated with a positive real economic impact (economic activity growth proxies and increased investors' confidence) exert a negative influence on correlations, while the contractive forces (higher uncertainty and tighter credit conditions) exacerbate correlations and are estimated with a positive sign irrespective of the specification chosen. Lastly, the crisis break mostly intensifies the macro-variables impact on the evolution of correlations with the exception of geopolitical risk, where the geopolitical tensions effect is alleviated following the advent of the global turmoil.

Overall, the counter-cyclical behavior of correlations is explained by the negative sign effect of higher economic activity and confidence and the magnifying impact of higher uncertainty and tighter credit conditions. Given that the business cycle downturn is associated with the adverse uncertainty effects on activity (Caggiano et al. 2017, Colombo, 2013, Jones and Olson, 2013), it is economically plausible for the uncertainty to drive financial correlations higher both directly and indirectly, inflating the other macro- 
factors' impact, as well. Therefore, our study contributes to three main strands of empirical macro-finance literature. Firstly, we add to the research on financial markets correlations with multiple asset classes by providing evidence on the common macro-drivers of cross-asset interdependence and contagion. Secondly, our analysis on the macro-relevance of financial markets correlations enriches the macro-financial linkages bibliography. Thirdly and most importantly, we focus on the economic policy uncertainty destabilizing effect on financial correlations, which has not yet been assessed in the burgeoning uncertainty literature. Evidence is still scant on the common forces behind the linkages of financial markets of equities, real estate, and commodities. We address this issue using both daily and monthly macro-proxies, with novel findings useful for financial analysts and policymakers. On the one hand, financial analysts mostly rely on daily frequency correlations modeling in asset allocation, portfolio optimization (considering the diversification benefits), hedging, derivatives pricing, and risk management. On the other hand, policymakers apply lower frequency data in devising drastic policies to proactively act or directly respond to systemic risk build-ups that materialize in periods of elevated financial correlations.

The paper proceeds as follows. The next Section reviews the correlations and policy uncertainty literature. In Section 3, we detail the methodology defining our empirical models and the data used. Section 4 presents the estimation results of the correlation determinants for both daily and monthly frequencies. Section 5 focuses on the policy uncertainty effect on each macro-variable that drives the correlations evolution. The following Section discusses the impact of the crisis break detected in the dynamic correlation series. Finally, Section 7 concludes the analysis.

\section{Literature Review}

Our literature review covers the three main pillars of research, we intend to contribute. We first discuss the financial correlations bibliography and highlight the limited evidence on their macro-relevance. The second part of our review is dedicated to the economic policy uncertainty literature and its macro-financial applications. Clearly, both sections refer to the macro-financial linkages research which is the third pillar of our empirical contribution.

\subsection{Financial Markets Dynamic Correlations}

During the last three decades, financial markets have become highly integrated. The study of the linkages between volatilities and co-volatilities of financial markets returns is a critical issue in risk management practice. The multivariate GARCH framework provides the tools to understand how financial volatilities move together over time and across markets. For thorough surveys of the available Multivariate GARCH models and their use in various fields of risk management, such as option pricing, hedging, and port- 
folio selection, see Bauwens et al. (2006) and Silvennoinen and Teräsvirta (2009). Following Bollerslev (1990), who added the Constant Conditional Correlations (CCC) to the multivariate GARCH, we moved to the time-varying correlations modeling with the Dynamic Conditional Correlations (DCC) of Engle (2002), the Asymmetric Dynamic Conditional Correlations (ADCC) of Cappiello et al. (2006), and, more recently, the Dynamic Equicorrelations (DECO) of Engle and Kelly (2012). The dynamic correlations equation specified by either the DCC, the ADCC or the DECO specification is widely applied to measure the interdependence of equity markets (see, for example, Karanasos et al., 2016, Pappas et al., 2016), commodities (Kang et al., 2017b, Karanasos et al., 2018), and securitized real estate (Chong et al., 2012, Liow et al., 2015).

Apart from correlations across countries or sectors for a single asset class, the empirical finance literature provides an extensive amount of evidence on cross-asset dynamic correlations but without elucidating which macro-determinants might drive their evolution. Creti et al. (2013), for instance, investigate the commodity-stock market link, applying the DCC model. They prove that correlations become highly volatile around the recent financial crisis and draw interesting conclusions on the financialization of commodity markets. In the DCC context, Lucey and Li (2015) examine the time-varying correlations of commodities with stocks and bonds to prove the safe haven properties of four precious metals. Relying on the ADCC model, Liow (2012) analyze the real estate-stock markets correlations which are found to have significantly increased prior to and during the global crisis. Moreover, Case et al. (2012) provide a portfolio optimization application of the DCC specification for the real estate-stock correlations. The third pair of interest, commodities-real estate, is explored by Huang and Zhong (2013), who add in their DCC analysis Treasury securities and employ their trivariate correlation results on a time-varying Sharpe ratio calculation.

Among the few studies that have explored the cross-asset dynamic conditional correlation determinants is Yang et al. (2012). They use the ADCC model to explore the correlation dynamics from 1999 until 2008 between the US indices for stocks (S\&P 500) and securitized real estate (REITs), adding US corporate bonds and investment-grade commercial mortgage-backed securities indices, as well, to the correlation puzzle. They attempt to explain the four assets' interdependence by regressing the ADCCgenerated pairwise correlations on the default, term, and mortgage spreads, and the VIX implied volatility index. Furthermore, Batten et al. (2019) find the drivers of the stock-commodities DCCs used in hedge ratio calculation for stock-oil portfolios, with the global financial crisis and VIX playing the most important role. Finally, Behmiri et al. (2019) focus on a single asset class, the commodity market, and explore the determinants of various commodities dynamic correlations by regressing the DCC series on macroeconomic fundamentals, financial market characteristics, and speculative activity proxies. 


\subsection{Economic Policy Uncertainty}

Turning from dynamic correlations to the Economic Policy Uncertainty (EPU) literature, we, first, review the uncertainty measurement approaches in order to discuss the relative merits of the EPU index, which justify our decision to select EPU as our economic uncertainty proxy. Further, we briefly present the empirical evidence with applications of the EPU indices. Lastly, we refer to the use of EPU in the financial correlations research and, more precisely, the DCC framework.

It is clear that the literature on financial correlation dynamics has mostly ignored important macrofactors that affect the correlation pattern. In this vein, we focus on the role of uncertainty, besides other macro-proxies, in correlations modeling using the news-based EPU index, the sole uncertainty metric provided with a daily frequency by Baker et al. (2016) for the US and the UK (apart from the monthly indices for multiple countries) and which is considered to be the most comprehensive one, including both economic and policy-related constituents of uncertainty. Our motivation to explore the uncertainty effects on financial correlations derives from the recent resurgence of research interest in uncertainty, partly stimulated by the global crisis of 2008 and primarily reflected in the definition and measurement debate of this 'amorphous' concept by economists (Bloom, 2014). Following the Knightian definition (Knight, 1921) and the early studies on uncertainty by Bernanke (1983) and Dixit and Pindyck (1994), academics and practitioners have attempted to quantify this latent variable objectively to reflect the prevailing uncertainty in the process of decision making by economic agents. Consumers' spending and saving behavior, firms' hiring, financing, and investment choices, investors' asset allocation, central banks, and government policy decisions are heavily affected by their 'inability to forecast the likelihood of events happening' according to Frank Knight (Bloom, 2014). In principle, the prevailing uncertainty is evidenced to elicit potent disruptions in the real economy through financial and credit markets, dampening the general confidence and discouraging market participants from doing business. Undoubtedly, in times of elevated uncertainty, households tend to reduce consumption and increase precautionary savings and firms postpone investments ('wait and see' tactics) and refrain from hiring. Similarly, investors in financial markets concerned with uncertainty react, evoking the progressive slowdown or often the steep fall of asset price returns (either through the discount rate or the cash flow channel) and synchronously driving volatility and correlation to jump (Pastor and Veronesi, 2013). Simultaneously, in the credit markets uncertainty commands a risk premium in the cost of capital, foreshadowing the possible meteoric rise of the financing cost for firms (Alessandri and Mumtaz, 2019) and undermining general trust in the financial system. 


\subsubsection{The Uncertainty Measurement Approaches}

Since economic uncertainty constitutes one of the most debated factors to explain the recent crisis with the ensuing persistent slowdown and the unexpectedly sluggish recovery, eminent scholars responded to the challenge of quantifying such an unobservable variable in order to test its influence on economic activity. They employed a wide variety of econometric forecasting techniques and some more novel text-mining and machine-learning methods on time series data of economic variables, survey data, news stories, Google search volumes or even internet-clicks data to compute tangible measures of uncertainty. Beyond the acknowledged consensus on the use of financial markets implied volatility (e.g. VIX) as a reliable proxy of uncertainty in macro-financial modeling (Bloom, 2009, Bekaert et al., 2013), another rather traditional approach to gauge uncertainty has been the second moment of the time series of a macroeconomic or financial indicator (e.g. GARCH conditional variance in Fountas and Karanasos, 2007). More recently, under the pure econometrics approach, academics have addressed the quantification problem by formalizing economic uncertainty measures with sophisticated large-scale structural models on macroeconomic and financial datasets (Mumtaz and Theodoridis, 2018, Jurado et al., 2015, Carriero et al., 2018). A further strand of the well-established uncertainty literature has produced survey-based uncertainty measures, using among others the Surveys of Professional Forecasters (Scotti, 2016, Rossi and Sekhposyan, 2015, Jo and Sekkel, 2019).

In light of the seminal paper of Baker et al. (2016), a considerable number of studies have developed news-based uncertainty measures, which are gaining enormous popularity. Baker et al. (2016) were among the first scholars that applied textual analysis to construct the EPU index by calculating the frequency of references to uncertainty concerning economic policy in leading newspapers (count of keywords like uncertainty and economic policy). The EPU index is computed nowadays for many countries (see the indices publicly available by the majority of EPU authors on the site maintained by Baker, Bloom, and Davis, http://www.policyuncertainty.com/) with a monthly frequency (daily EPUs are constructed only for US and UK) and extended to several categorical subindices (i.e. uncertainty on fiscal, monetary, trade policy, etc.). The motivation behind the news-based indicators lies in the consideration that the press is a reliable and timely mirror of the agents' expectations and economic sentiment. Common knowledge suggests that newspapers should outline the economic reality according to readers' information demand, interests and expectations in order to maintain their audience. Baker et al. (2016) opened up a new strand of research with a growing body of bibliography which markedly focused on textual search and machine learning methods to construct similar news-based policy uncertainty indices, with the mounting interest of many scholars in improving such methodologies (Brogaard and Detzel, 2015, Larsen and Thorsrud, 2018). Besides pure policy-related uncertainty, several types of uncertainty have been created using 
textual analysis of news coverage, for example, the Geopolitical Risk indicator by Caldara and Iacoviello (2018) and the House Price Uncertainty index (HPU) by the UK Housing Observatory at Lancaster University (Yusupova et al., 2019). In line with the news-based uncertainty measures extracted through text mining algorithms on newspaper articles, there are two more approaches in this bibliography part: the sophisticated and ready-to-use news indicators provided by news agencies like Bloomberg and Thomson Reuters (see, for example, Caporale et al., 2018) and the internet search engines volume metrics (Google trends in Castelnuovo and Tran, 2017, Wikipedia searches in Vlastakis and Markellos, 2012, and Bitly click data in Benamar et al., 2018). Several uncertainty indices are derived from internet search intensity of keywords related to uncertainty or to an economic term, event or variable, indicating that such terms have attracted the attention of the general public due to uncertainty.

Within the long stream of literature on news-based indices, the key conceptual difference between the two main approaches (the news coverage and the internet search engines or clicks) lies in the information perspective they employ. The former is applied to the information supply side, while the latter on the demand side. We strongly believe that the supply side is more reliable for quantifying uncertainty. On the one hand, it is commonplace that newspapers as information providers should reflect the general mood in order to attract and maintain their audience. Thus, the media content is of immense value for gauging uncertainty. On the other hand, the demand side, directly connected to economic psychology, is measured by internet queries and news clicks intensity. Thus, it may create bias on the real uncertainty level since the clicks volume also depends on people's free time and internet access, apart from implying attention or information search as a response to uncertainty. Consistent with our view that news-based indices constructed on the information supply side are more appealing, in this paper, we focus on EPU. The intuition behind our preference for using the novel news-based EPU index is straightforward given the numerous attractive features, suggestive of its usefulness. The merits of the EPU index are summarized as follows: i) the insights derived from real-time news coverage, ii) the timeliness of news arrival with sound signaling potential, iii) the availability for major economies, iv) the policy-sensitive feature included in the uncertainty measurement, and v) the consistency as substantiated in the ample empirical support of its explanatory and predictive power in macro-financial models. Given the facts that i) EPU relies on daily news, ii) political news dominates the markets, and iii) the construction of the index includes policy-related concerns apart from economic terms alone, we regard it as a number that fits all, both macroeconomic and financial reality, in a timely manner. The model- and survey-based uncertainty proxies cannot be as up-to-date as EPU due to their reliance on the history of economic variables or the non-real-time survey responses by forecasters, whose disagreement or forecast error dispersion do not necessarily suggest the omnipresence of uncertainty in the economy. Newspapers can be thought of as the best illustration of the general public's (households, corporations, investors and governments) feeling 
in terms of uncertainty, although they are occasionally criticized in relation to their objectivity, that they may create news instead of simply transmitting it. In this case, the use of wide-ranging sources to construct the EPU indices eliminates the possibility of one or more newspapers attempting to inflate or conceal the ubiquitous uncertainty.

\subsubsection{Economic Policy Uncertainty and Dynamic Correlations}

It is important to note here that news textual analysis is used broadly in various scientific fields to quantify societal trends and public opinion. Nowadays, this novel strategy has inevitably come to the aid of economic science for measuring variables not directly observable, such as uncertainty, leading to the lengthy catalogue of the renowned EPU indices. These indices have gained remarkable popularity in numerous applications in economics and finance. Interestingly, they have recently started showing up even in media reports and investment recommendations. A voluminous literature has mushroomed over three axes of research: connecting EPU with macro-aggregates, microeconomic data, and financial variables. The large bulk of the EPU literature investigates the explanatory or the predictive power of EPU on business cycles (with the leading macro-variables included: unemployment in Caggiano et al., 2017, output and inflation in Colombo, 2013, Jones and Olson, 2013, Karaman and Yildirim-Karaman, 2019, economic development in Scheffel, 2016, monetary dynamics in Aastveit et al., 2017, Tarassow, 2019, yield curve slope in Connolly et al., 2018, foreign exchange rates in Kido, 2016, bank credit and bailouts in Bordo et al., 2016, Caliendo et al., 2018, EPU spillovers in Gabauer and Gupta, 2018, Balli et al., 2017, Klößner and Sekkel, 2014), on asset prices, returns, volatilities and correlations (equities in Pastor and Veronesi, 2012, Kelly et al., 2016, bonds in Bernal et al., 2016, stock-bond correlation in Li et al., 2015, commodities in Antonakakis et al., 2014, Aloui et al., 2016, Andreasson et al., 2016, Kang et al., 2017a, Fang et al., 2018a, Bakas and Triantafyllou, 2019, real estate in Christou et al., 2017, sovereign credit ratings in Boumparis et al., 2017, CDS spreads in Wisniewski and Lambe, 2015, cryptocurrencies in Fang et al., 2019), and at the micro-level on corporate accounting numbers (Gulen and Ion, 2015, Pham, 2019, Zhong et al., 2019), firm and household decisions (Nagar et al., 2018, Ben-David et al., 2018). Granger causality tests, Structural VARs, Diebold-Yilmaz (DY) dynamic interconnectedness (Diebold and Yilmaz, 2009), Quantile regressions, GARCH models with MIDAS specifications in many cases, when variables of mixed frequencies are involved, and with Dynamic Conditional Correlations (Engle, 2002), when the dynamic nature of correlations is considered, are among the most common modeling approaches adopted in the EPU empirical evidence studies.

Despite the substantial advances in the EPU research which originated with the advent of the recent crisis, the literature on the correlation dynamics of macro-financial variables with uncertainty is still in its infancy. The modeling approach mainly employed is the multivariate GARCH with DCC and the 
various DCC-extensions developed thereafter. While most empirical exercises connect EPU indices with macro-indicators or several asset classes through the DCC models, showing a great deal of time-variation in this interconnectedness, there exists little evidence on the time-varying correlations of macros and financials explained by the EPU level or growth. The EPU as a driving force of the integration dynamics across economies and markets has been remarkably overlooked or barely discussed. Since integration is inseparable from financial and macro-fundamentals, it is imperative to detect and understand the role of uncertainty in the integration process. In the macroeconomics spectrum, Jones and Olson (2013) were the first to apply the DCC model for EPU, inflation, and output, running the EPU index in pairs with the other two variables. From the two bivariate specifications, they find that the correlation between uncertainty and output is always negative, while the EPU-inflation pair gives mostly a negative correlation sign from 1985 until the late 1990s and then it turns to positive. In the finance literature, Antonakakis et al. (2013) compute the DCCs between EPU, S\&P 500 stock index returns and implied volatility (VIX) pairwise. The EPU-VIX correlation is positive and the EPU-returns negative, as expected, since elevated uncertainty depresses stock market performance and goes alongside higher stock market volatility. They further regress DCCs on demand oil price shocks and US recession dummies. Dakhlaoui and Aloui (2016) investigate the volatility spillovers with multivariate GARCH models between the US EPU and BRICS stock indices and compute time-varying correlations as well. Moreover, Kido (2016) calculates the DCCs between real effective exchange rates and EPU, resulting in a negative sign for most currencies.

Reviewing the few commendable attempts to explain the behavior of financial correlations with EPU, we can trace back this link to Pastor and Veronesi (2013), who were the first to associate stock markets with EPU using simple OLS regressions of stock returns, volatilities and correlations (unconditional) on the EPU index, whose coefficient sign was consistently positive for correlations and volatilities and negative for returns. More recently, Skintzi (2019) with stock-bonds DCCs and Behmiri et al. (2019) with commodities DCCs have carried out regression analyses to explain the correlation dynamics through macro-financial regressors, including stock market implied volatility (VIX), as a proxy of uncertainty, but not the more comprehensive measure, namely the EPU index. Beneki et al. (2019), more related to our idea of explaining the correlation dynamics with EPU, regress the time-varying correlations (produced by the BEKK model) between two major cryptocurrencies on EPU, finding a significant positive effect of uncertainty on the Ethereum-Bitcoin correlation pair, consistent with the arguments and results in Pastor and Veronesi (2013). In this vein, Fang et al. (2019) apply the DCC-MIDAS of Colacito et al. (2011) to study the effect of global EPU on Bitcoin correlation with global equities, commodities, and bonds. Batten et al. (2019) and Fang et al. (2018b) explain the stock-oil dynamic correlations with the EPU index, used as a regressor in the DCC-driven hedge ratios and the DCC-MIDAS long-run component, respectively. Lastly, Li et al. (2015) focus on the stock-bonds dynamic conditional correlations and 
confirm the negative relation between EPU and the stock-bonds nexus, grounded on the flight-to-quality hypothesis.

Despite the rapidly growing EPU literature, it appears that the empirical work on the conditional correlation dynamics driven by EPU is limited, with evidence still scant. Therefore, the present study fills a notable gap in the extant EPU literature. We elucidate whether EPU exerts considerable influence directly on global cross-asset correlations and indirectly on the other macro-factors' effect on correlations. Our work differs from the existing policy uncertainty literature in the use of EPU as a dynamic equicorrelations determinant both with daily and monthly frequencies. The particular EPU link has not yet been thoroughly assessed. Therefore, we define the macro-drivers of the correlations calculated by the innovative Dynamic Equicorrelations model of Engle and Kelly (2012) with the GJR-GARCH specification of Glosten et al. (1993) for the conditional variance equation, as outlined in the following section.

\section{Methodology and Data Description}

Our major objective and research contribution is to shed light on the macro-drivers of cross-asset correlations and scrutinize the critical EPU role in the correlation process. The first step is to calculate the dynamic correlations and then use the correlation series as dependent variable in time series regressions with the relevant macro-determinants included as regressors.

In this context, the most common method in finance to investigate the financial correlation dynamics of daily returns lies inside the multivariate GARCH framework. Multivariate GARCH models describe the time-varying nature of conditional co-volatilities and correlations. Engle (2002) was among the pioneers that allowed for dynamic conditional correlations in combination with any univariate GARCH variance specification. The empirical methodology we adapt in this study is the GJR-GARCH-DECO model. We combine the mean process of daily equity, real estate, and commodity index returns with the asymmetric Garch of Glosten et al. (1993) for the conditional variance and the Dynamic Equicorrelations of Engle and Kelly (2012) to calculate the three correlation pairs among the three asset returns. The advantages of the particular combination that support our preference for the DECO amongst the existing DCC variations and the GJR out of the different GARCH models are as follows: i) The DECO specification computes efficiently conditional correlations equal for all pairs of returns to reduce the computation load of high-dimensional correlation matrices (see, for example, Pan et al., 2016 for a discussion on the DECO computational superiority over the existing multivariate GARCH models with dynamic correlations). ii) The GJR-GARCH process is a simple GARCH specification without computational or presentational difficulties. It takes into consideration the asymmetric effect from negative returns on the conditional variance, estimating the leverage term apart from the arch and garch effects of the basic GARCH $(1,1)$ 
model (Bollerslev, 1986).

In what follows across this Section, we detail our GJR-GARCH-DECO bivariate specification estimated for the combinations of the three index returns under investigation: equities-real estate, equitiescommodities, and commodities-real estate. We additionally present the time series regression model of the correlation pairs (calculated from the DECO model estimations) on the macroeconomic regressors of uncertainty, credit conditions, economic activity, sentiment, and geopolitical risk. Finally, we describe the data used in our empirical analysis.

\subsection{The Empirical Model}

\subsubsection{The GJR-GARCH-DECO Specification}

The first estimation step consists of computing the dynamic pairwise correlations between the benchmark index returns of equities, real estate and commodities. The three pairs of daily returns are modeled through the GJR-GARCH-DECO bivariate specification. Let us define the $N$-dimensional column vector of the returns $\mathbf{r}_{t}$ as $\mathbf{r}_{t}=\left[r_{i t}\right]_{i=1, \ldots, N}$ and the corresponding residual vector $\varepsilon_{t}$ as $\varepsilon_{t}=\left[\varepsilon_{i t}\right]_{i=1, \ldots, N}$. The structure of the mean equation is given by

$$
\mathbf{r}_{t}=\phi+\varepsilon_{t}
$$

where $\boldsymbol{\phi}=\left[\phi_{i}\right]_{i=1, \ldots, N}$ is an $N \times 1$ vector of constants. For example, the bivariate model is given by

$$
\left[\begin{array}{c}
r_{1 t} \\
r_{2 t}
\end{array}\right]=\left[\begin{array}{l}
\phi_{1} \\
\phi_{2}
\end{array}\right]+\left[\begin{array}{l}
\varepsilon_{1 t} \\
\varepsilon_{2 t}
\end{array}\right] .
$$

Regarding $\varepsilon_{t}$ we assume that it is conditionally normally distributed with mean vector $\mathbf{0}$, conditional covariance matrix $\boldsymbol{\Sigma}_{t}=\mathbb{E}\left(\varepsilon_{t} \varepsilon_{t}^{\prime} \mid \mathcal{F}_{t-1}\right)=\left[\sigma_{i j, t}\right]_{i, j=1, \ldots, N}\left(\mathcal{F}_{t-1}\right.$ denotes the information available at time t), and conditional variance vector $\boldsymbol{\sigma}_{t}=\mathbb{E}\left(\varepsilon_{t}^{\wedge 2} \mid \mathcal{F}_{t-1}\right)=\left[\sigma_{i i, t}\right]_{i=1, \ldots, N}$ or $\boldsymbol{\sigma}_{t}=\left(\mathbf{I}_{N} \odot \boldsymbol{\Sigma}_{t}\right) \mathbf{i}$, where $\mathbf{I}_{N}$ is the identity matrix of order $N, \mathbf{i}$ is an $N \times 1$ vector of ones, $\odot$ is a Hadamard product, and $\wedge$ denotes element-wise exponentiation; $\boldsymbol{\sigma}_{t}$ follows a multivariate GJR-GARCH $(1,1)$ model (see below).

Notice that $\varepsilon_{t}$ can be written as $\left(\mathbf{e}_{t} \odot \mathbf{q}_{t}^{\wedge-1 / 2}\right) \odot \boldsymbol{\sigma}_{t}^{\wedge 1 / 2}$ where $\mathbf{e}_{t}=\left[e_{i t}\right]_{i=1, \ldots N}$ is conditionally normally distributed with mean vector $\mathbf{0}$, time-varying covariance (symmetric positive definite) matrix $\mathbf{Q}_{t}=\left[q_{i j, t}\right]_{i, j=1, \ldots, N}$ and variance vector $\mathbf{q}_{t}=\left(\mathbf{I}_{N} \odot \mathbf{Q}_{t}\right) \mathbf{i}$. It follows that

$$
\begin{aligned}
\sigma_{i j, t} & =\mathbb{E}\left(\varepsilon_{i t} \varepsilon_{j t} \mid \mathcal{F}_{t-1}\right)=\mathbb{E}\left(\frac{e_{i t} e_{j t}}{\sqrt{q_{i i, t} q_{j j, t}}} \sqrt{\sigma_{i i, t} \sigma_{j j, t}} \mid \mathcal{F}_{t-1}\right) \\
& =\frac{\sqrt{\sigma_{i i, t} \sigma_{j j, t}}}{\sqrt{q_{i i, t} q_{j j, t}}} \mathbb{E}\left(e_{i t} e_{j t} \mid \mathcal{F}_{t-1}\right)=\sqrt{\sigma_{i i, t} \sigma_{j j, t}} \frac{q_{i j, t}}{\sqrt{q_{i i, t} q_{j j, t}}}=\sqrt{\sigma_{i i, t} \sigma_{j j, t}} \rho_{i j, t} .
\end{aligned}
$$

Most importantly, we allow for time-varying correlations, $\rho_{i j, t}=\sigma_{i j, t} / \sqrt{\sigma_{i i, t} \sigma_{j j, t}},\left|\rho_{i j, t}\right| \leq 1(i, j=$ $1, \ldots, N) \forall t$, instead of the constant ones, $\rho_{i j}$, defined by Bollerslev (1990). 
The covariance matrix $\boldsymbol{\Sigma}_{t}$ can be expressed as

$$
\boldsymbol{\Sigma}_{t}=\left(I_{N} \odot \boldsymbol{\Sigma}_{t}^{\wedge 1 / 2}\right) R_{t}\left(I_{N} \odot \boldsymbol{\Sigma}_{t}^{\wedge 1 / 2}\right),
$$

where $R_{t}=\left[\rho_{i j, t}\right]_{i, j=1, \ldots, N}$ is the $N \times N$ symmetric positive semi-definite time-varying correlation matrix with ones on the diagonal $\left(\rho_{i i, t}=1\right)$ and the off-diagonal elements less than one in absolute value.

Next, the structure of the conditional variance is specified as in Glosten et al. (1993). The multivariate GJR-GARCH( $(1,1)$ we estimate is specified as follows:

$$
\boldsymbol{\beta}(L) \odot \boldsymbol{\sigma}_{t}^{\bar{\lambda}}=\boldsymbol{\omega}+[\boldsymbol{\alpha}(L)+\gamma(L)] \odot \boldsymbol{\varepsilon}_{t},
$$

where $\boldsymbol{\beta}(L)=\left[1-\beta_{i} L\right]_{i=1, \ldots, N}$, and $\boldsymbol{\omega}=\left[\omega_{i}\right]_{i=1, \ldots, N}, \omega_{i} \in(0, \infty) ; \boldsymbol{\alpha}(L)=\left[\alpha_{i} L\right]_{i=1, \ldots, N}, \boldsymbol{\gamma}(L)=\left[\gamma_{i} L s_{i t}\right]_{i=1, \ldots, N}$; the $\gamma_{i}$ are the leverage coefficients, and $s_{t}=0.5\left[1-\operatorname{sign}\left(\varepsilon_{t}\right)\right]$, that is, $s_{t}=1$ if $\varepsilon_{t}<0$ and 0 otherwise. In other words, each conditional variance follows a GJR-GARCH $(1,1)$ model:

$$
\left(1-\beta_{i} L\right) \sigma_{i i, t}=\omega_{i}+\left(\alpha_{i}+\gamma_{i} s_{i t-1}\right) L\left(\varepsilon_{i t}^{2}\right), i=1, \ldots, N
$$

where positive $\gamma_{i}$ means a larger contribution of negative 'shocks' to the volatility process.

Moreover, the structure of $\mathbf{R}_{t}$ according to the DCC $(1,1)$ model of Engle (2002) is given by

$$
\begin{gathered}
\mathbf{R}_{t}^{D C C}=\left(I_{N} \odot \mathbf{Q}_{t}^{\wedge-1 / 2}\right) \mathbf{Q}_{t}\left(I_{N} \odot \mathbf{Q}_{t}^{\wedge-1 / 2}\right), \\
\mathbf{Q}_{t}=(1-a-b) \mathbf{Q}+a \mathbf{e}_{t-1}^{\wedge 1 / 2} \mathbf{e}_{t-1}^{\prime \wedge 1 / 2}+b \mathbf{Q}_{t-1},
\end{gathered}
$$

where $\mathbf{Q}=\mathbb{E}\left(\mathbf{Q}_{t}\right)=\left[q_{i j}\right]_{i, j=1, \ldots, N}, a$ and $b$ are nonnegative scalar parameters satisfying $a+b<1$. It is clear that Engle (2002) specifies the conditional correlations as a weighted sum of past correlations, since the $\mathbf{Q}_{t}$ is written as a GARCH process and then transformed to a correlation matrix.

In the bivariate case, the $\operatorname{DCC}(1,1)$ conditional correlation coefficient $\rho_{12, t}$ is expressed as follows:

$$
\begin{gathered}
\rho_{12, t}^{D C C}=\frac{q_{12, t}}{\sqrt{q_{11, t} q_{22, t}}}, \\
q_{12, t}=(1-a-b) q_{12}+a e_{1, t-1} e_{2, t-1}+b q_{12, t-1}, \\
q_{11, t}=(1-a-b) q_{11}+a e_{1, t-1}^{2}+b q_{11, t-1}, \\
q_{22, t}=(1-a-b) q_{22}+a e_{2, t-1}^{2}+b q_{22, t-1} .
\end{gathered}
$$

For computational ease, Engle and Kelly (2012) impose a critical assumption to the calculation of $\mathbf{R}_{t}^{D C C}$ model in order to estimate dynamic equicorrelation matrices. They assume that each returns' pair has the same correlation, meaning that $\rho_{i j, t}=\rho_{j i, t}$. According to Engle and Kelly (2012), the DECO correlation in the bivariate case for assets $N=2, \rho_{12, t}^{D E C O}$, equals the average of the respective 
DCC correlations, $\rho_{12, t}^{D C C}$ and $\rho_{21, t}^{D C C}$ (the off-diagonal elements of $\mathbf{Q}_{t}$ ). Thus, the $\operatorname{DECO}(1,1)$ correlation matrix is defined as follows:

$$
\begin{aligned}
\mathbf{R}_{t}^{D E C O} & =\left(1-\rho_{i j, t}^{D E C O}\right) I_{N}+\rho_{i j, t}^{D E C O} J_{N} \\
\rho_{i j, t}^{D E C O} & =\frac{2}{N(N-1)} \sum_{i=1}^{N-1} \sum_{j=i+1}^{N} \frac{q_{i j, t}}{\sqrt{q_{i i, t} q_{j j, t}}},
\end{aligned}
$$

where $J_{N}$ the $N \times N$ matrix of ones.

\subsubsection{The Equicorrelations Regression Model}

The second step of our empirical analysis consists of the regression of the daily dynamic equicorrelations (computed through the DECO model of the first step) on the macro-drivers of the cross-asset correlations evolution. The Fisher transformation of correlations is first applied to unbound the correlations from the $[-1,1]$ interval. The resulting daily time series $D E C O_{i j, t}$ is calculated as follows: $D E C O_{i j, t}=$ $\log \left(\frac{1+\rho_{i j, t}^{D E C}}{1-\rho_{i j, t}^{D E C O}}\right)$. The daily correlations $D E C O_{i j, t}$ are regressed on the daily proxies of policy $\left(E P U_{t}\right)$ and financial $\left(F U_{t}\right)$ uncertainty, credit conditions $\left(C R_{t}\right)$, and economic activity $\left(E C_{t}\right)$. The regressors selected are tested for their contemporaneous and the immediate lag effect (first lag) on correlations. In the Autoregressive Distributed Lag (ARDL) context, we apply a stepwise algorithm that tests both contemporaneous and causal effects and selects the best model according to the coefficients' significance, the adjusted $R^{2}\left(\bar{R}^{2}\right)$ and the information criteria (IC: AIC and BIC are the Akaike and the Schwartz Information Criteria, respectively). Furthermore, the first autoregressive lag, $D E C O_{i j, t-1}$, is used to remove any serial correlation from the model. To sum up, we address our main research question on the macro-determinants of cross-asset correlations evolution by estimating the following equation for each correlation pair:

$$
D E C O_{i j, t}=c_{0}+c_{1} D E C O_{i j, t-1}+c_{2} E P U_{t-n}+c_{3} F U_{t-n}+c_{4} C R_{t-n}+c_{5} E C_{t-n}+u_{i j, t},
$$

with $i j$ the two assets of the correlation pair, $n$ the time lag with values 0 , for the contemporaneous effect, and 1 , for the immediate causal effect, $c_{0}$ the regression's constant, and $u_{i j, t}$ the standard stochastic error term.

We further estimate the monthly average of each dynamic equicorrelation series extracted from the daily DECO model. After the Fisher transformation of the monthly averages, we regress the monthly dynamic equicorrelations, $m D E C O_{i j, t}$, on the first autoregressive lag, $m D E C O_{i j, t-1}$, and the monthly macroeconomic variables: economic policy uncertainty $\left(m E P U_{t}\right)$, credit conditions $\left(m C R_{t}\right)$, economic 
activity $\left(m E C_{t}\right)$, business $\left(B S_{t}\right)$, and consumer sentiment $\left(C S_{t}\right)$, and geopolitical risk $\left(G P R_{t}\right)$. The monthly time series regression is estimated with the following equation:

$$
\begin{aligned}
m D E C O_{i j, t}= & z_{0}+z_{1} m D E C O_{i j, t-1}+z_{2} m E P U_{t-n}+z_{3} m C R_{t-n}+z_{4} m E C_{t-n} \\
& +z_{5} B S_{t-n}+z_{6} C S_{t-n}+z_{7} G P R_{t-n}+U_{i j, t}
\end{aligned}
$$

with $z_{0}$ the regression's constant, and $U_{i j, t}$ the standard stochastic error term.

Finally, in the correlation regression models (eq. (10) and (11)), we add the EPU interaction terms, by multiplying the EPU variable with each macro-regressor other than the policy uncertainty. This is the way to investigate the EPU impact on the macro-drivers of correlation dynamics. Thus, we estimate the following regression equations for the daily, eq. (12), and the monthly, eq. (13), frequency, where the superscript ${ }^{E P U}$ denotes the coefficients of the EPU interaction terms:

$$
\begin{aligned}
D E C O_{i j, t}= & c_{0}+c_{1} D E C O_{i j, t-1}+c_{2} E P U_{t-n}+c_{3} F U_{t-n}+c_{3}^{E P U} E P U_{t-n} F U_{t-n} \\
& +c_{4} C R_{t-n}+c_{4}^{E P U} E P U_{t-n} C R_{t-n}+c_{5} E C_{t-n}+c_{5}^{E P U} E P U_{t-n} E C_{t-n}+u_{i j, t},
\end{aligned}
$$

$$
\begin{aligned}
m D E C O_{i j, t}= & z_{0}+z_{1} m D E C O_{i j, t-1}+z_{2} m E P U_{t-n}+z_{3} m C R_{t-n}+z_{3}^{E P U} m E P U_{t-n} m C R_{t-n} \quad(13) \\
& +z_{4} m E C_{t-n}+z_{4}^{E P U} m E P U_{t-n} m E C_{t-n}+z_{5} B S_{t-n}+z_{5}^{E P U} m E P U_{t-n} B S_{t-n} \\
& +z_{6} C S_{t-n}+z_{6}^{E P U} m E P U_{t-n} C S_{t-n}+z_{7} G P R_{t-n}+z_{7}^{E P U} m E P U_{t-n} G P R_{t-n}+U_{i j, t} .
\end{aligned}
$$

\subsection{Data Description}

We use daily data for three indices considered as benchmarks of the performance of global equity, real estate, and commodity markets. Our global benchmarks, sourced from Thomson Reuters Datastream, are as follows:

- MSCI World Equities index (MXWO): MXWO includes large- and mid-cap equities of 23 developed equity markets.

- Dow Jones Real Estate Investment Trusts index (REIT): For securitized real estate investments, we use REIT, consisting of all publicly US REITs in the Dow Jones stock index.

- Standard \& Poor's Global Commodity index (GSCI): GSCI comprises 24 commodities from all commodity sectors. 
Our sample covers the period from $03 / 01 / 2000$ to $01 / 03 / 2019$, giving a total of 4,809 daily observations or 230 monthly observations when we compute the monthly averages of the daily series (from January 2000 until February 2019). For each index, the continuously compounded return is estimated as: $r_{i t}=\left[\ln \left(P_{i, t}^{C}\right)-\ln \left(P_{i, t-1}^{C}\right)\right] \times 100$, with $P_{i, t}^{C}$ the daily closing price on day $t$ (see Figures 1-3). We estimate the bivariate GJR-GARCH-DECO specification for the three combinations constructed from the three return series to investigate the dynamic equicorrelations (see Figures 4-6) between:

- equities and real estate (MXWO-REIT)

- equities and commodities (MXWO-GSCI)

- commodities and real estate (GSCI-REIT)

Figures 1-6 clearly show that both returns and correlations are higher during the recent global financial crisis period. The dynamic equicorrelations, in particular, remain at higher levels after the crisis period than the pre-crisis levels of the early 2000s, signifying an accelerated post-crisis integration process of the financial markets for equities, real estate, and commodities.

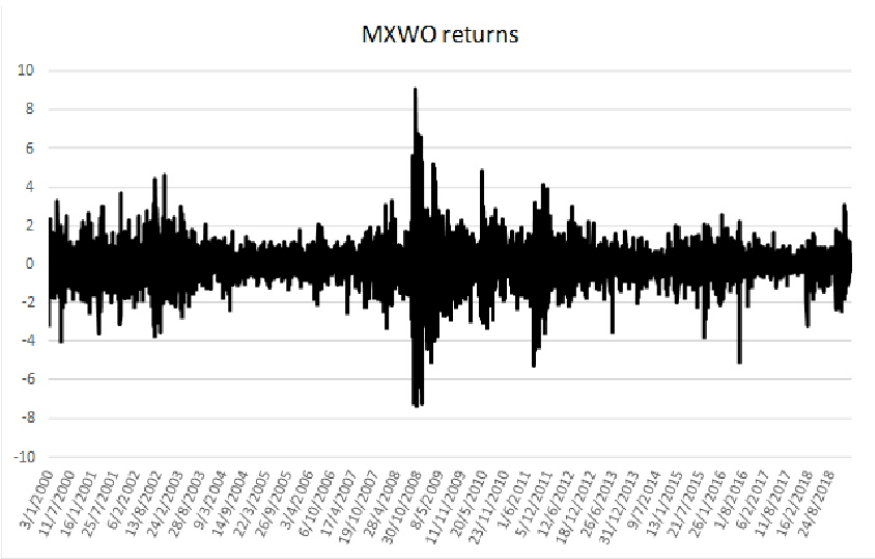

Figure 1. MSCI World Equities index returns

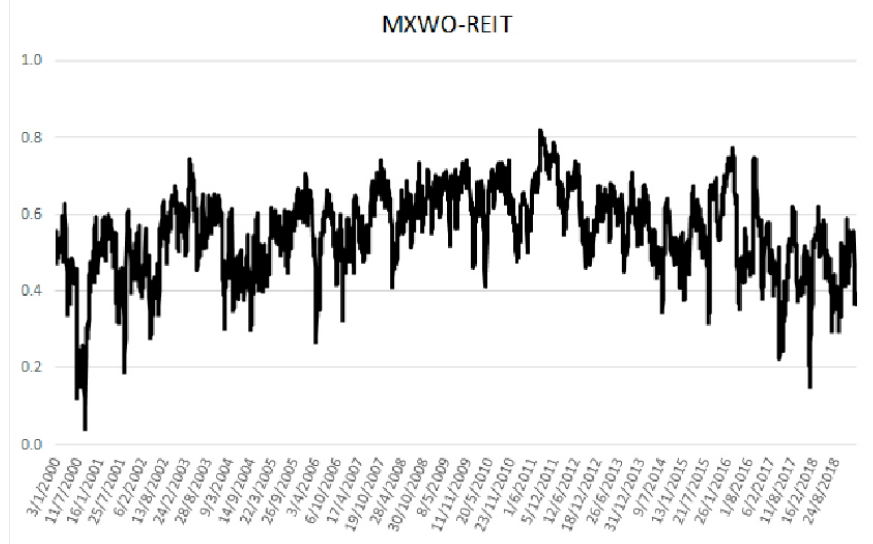

Figure 4. MXWO-REIT dynamic equicorrelations 


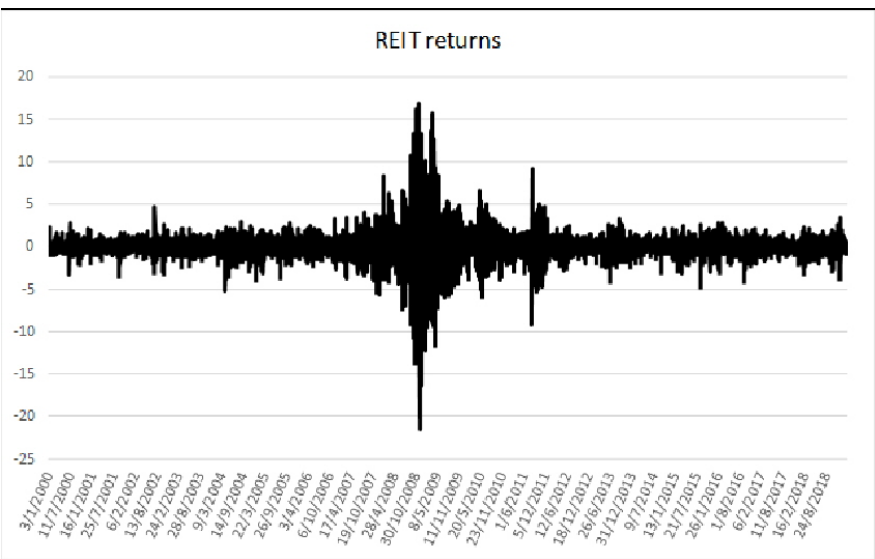

Figure 2. Dow Jones REITs index returns
MXWO-GSCI

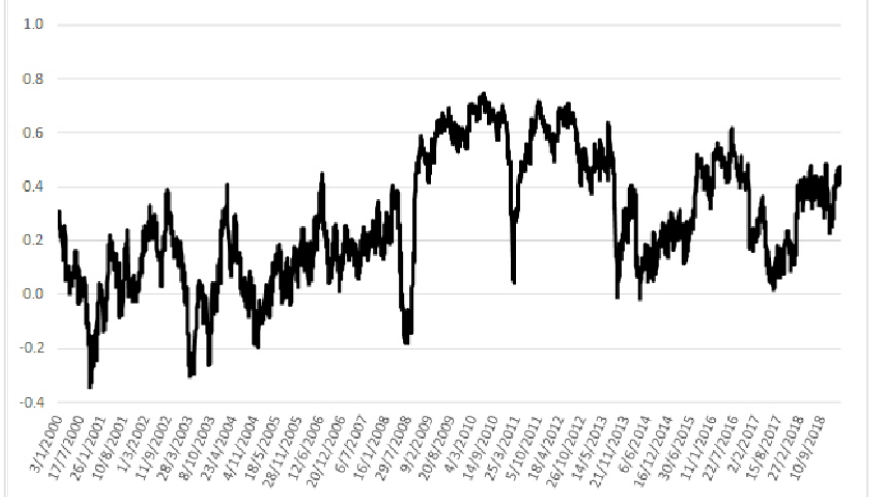

Figure 5. MXWO-GSCI dynamic equicorrelations

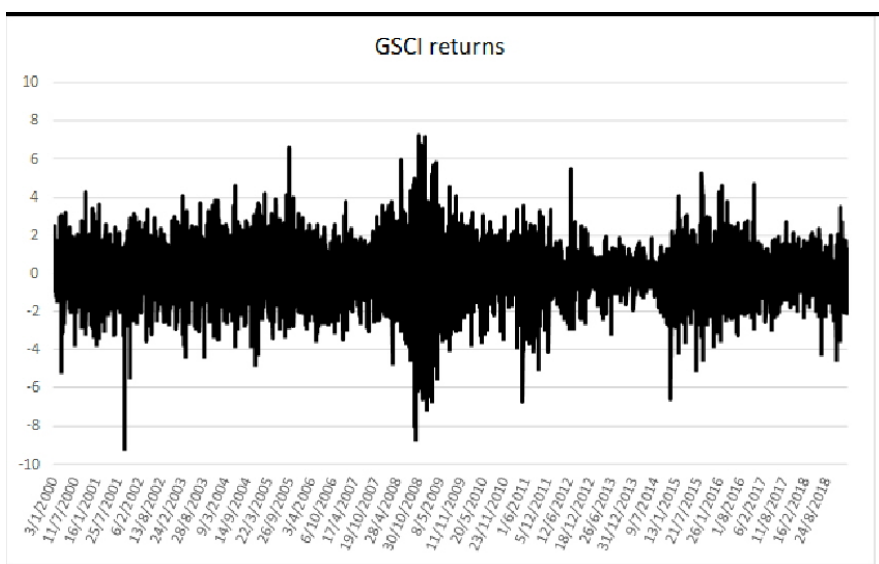

Figure 3. Standard \& Poor's GSCI index returns

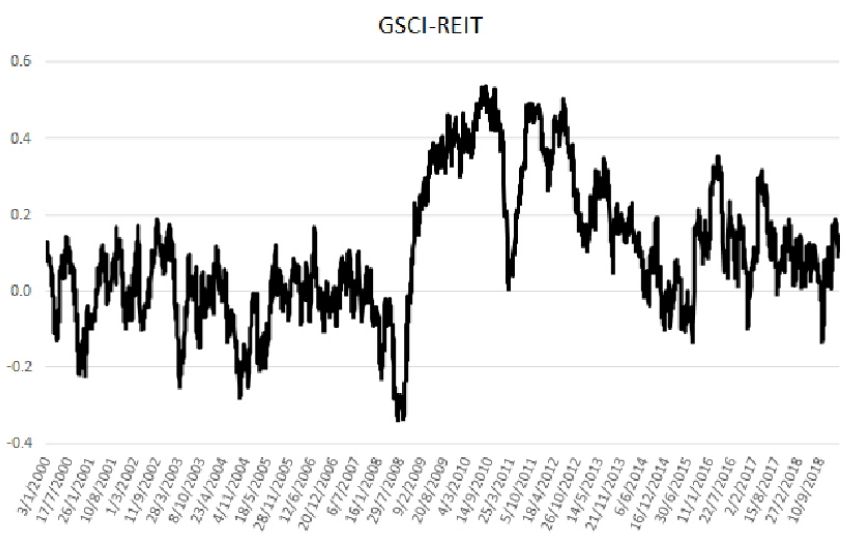

Figure 6. GSCI-REIT dynamic equicorrelations

The four daily macro-factors used as regressors in the daily equicorrelations $\left(D E C O_{i j, t}\right)$ regressions (equations (10) and (12)) provide evidence of the global macro-effects on the correlations evolution:

- The economic policy uncertainty $\left(E P U_{t}\right)$ is proxied by the daily US EPU index $\left(E P U_{U S, t}\right)$. Baker, Bloom, and Davis (https://www.policyuncertainty.com) construct EPU indices with a daily frequency for the US and the UK. We consider the US index more representative as a global factor for our cross-asset correlation study.

- The financial markets uncertainty $\left(F U_{t}\right)$ is proxied by the S\&P 500 implied volatility index VIX $\left(V I X_{U S, t}\right)$.

- The credit conditions $\left(C R_{t}\right)$ are proxied by the Merrill Lynch MOVE 1 month index $\left(M O V E_{U S, t}\right)$. The MOVE index is an estimate of the Option Implied Volatility of US Treasury bonds. It is the Treasury counterpart of the 'fear' index (VIX) for S\&P 500 and captures the sovereign credit 
market stance. Higher sovereign bond volatility denotes higher turbulence in the credit channel for sovereigns with direct spillovers to financial and non-financial corporations' credit conditions.

- The economic activity $\left(E C_{t}\right)$ is proxied by the US Yield Curve slope (or term spread), as calculated by the difference of the 10-year minus the 3 -month US Treasury bond yields $\left(Y C s l_{U S, t}\right)$. It is considered among the unique daily economic activity indicators since it has proved to be a powerful predictor of future economic activity (Estrella and Hardouvelis, 1991).

Our daily proxies are US macro-financial factors considered representative of the global economy. Figures 7-10 include the data graphs of our explanatory variables. Clearly, we observe a higher log-level of EPU, VIX, and MOVE during the crisis, where correlations also increased, and lower term spread in the US government bond curve. Interestingly, before the global crisis started, the term spread had turned to negative, implying an inverted Treasury yield curve that predicted the imminent economic activity slowdown.

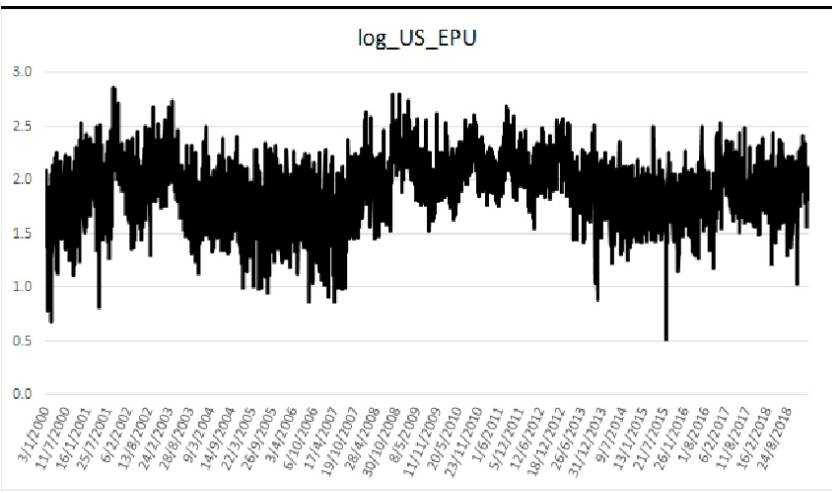

Figure 7. Daily US EPU index

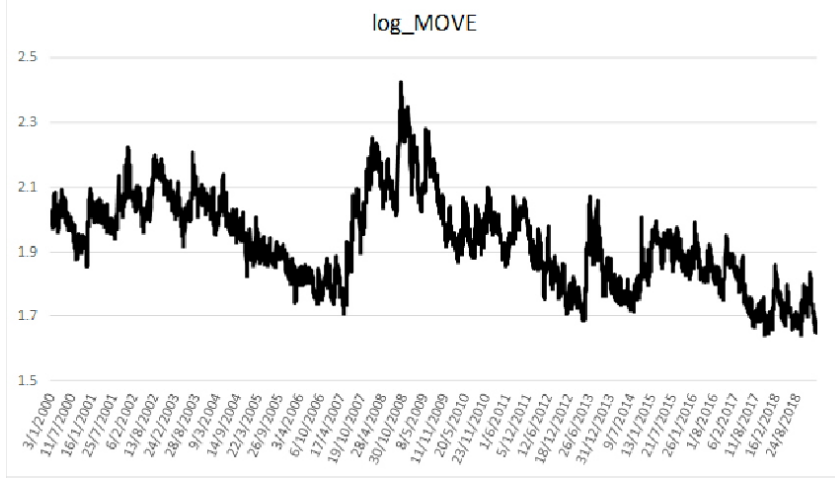

Figure 9. MOVE 1m index

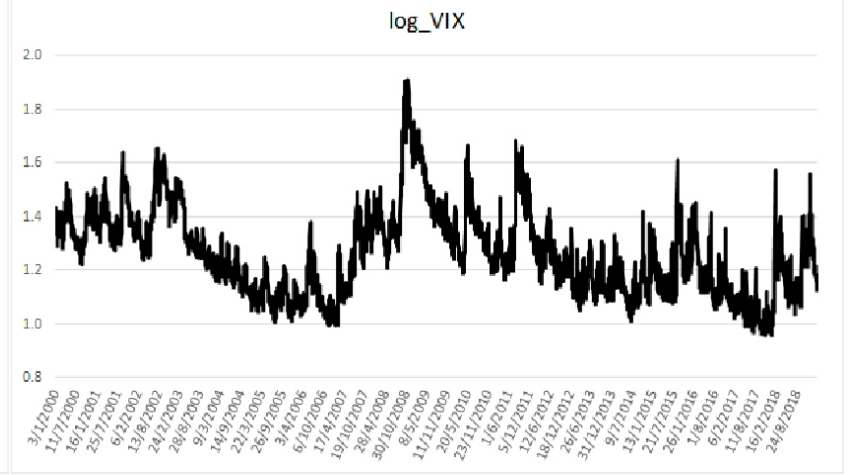

Figure 8. VIX index

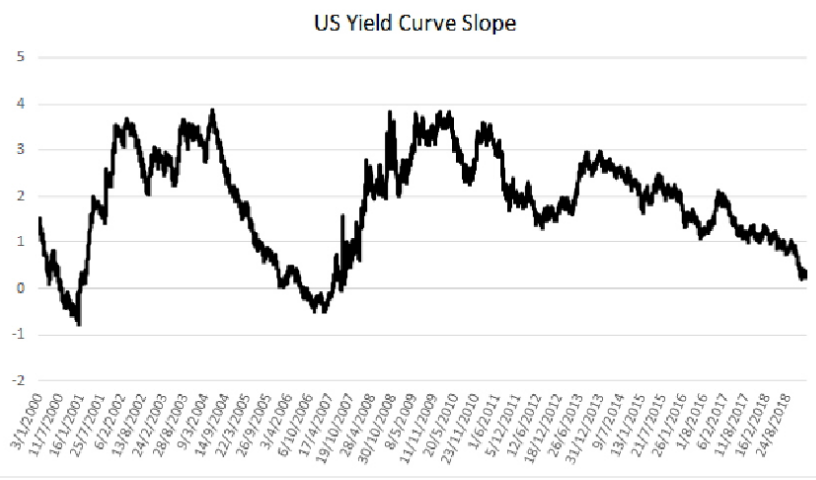

Figure 10. US Yield Curve slope 
In the monthly correlations $\left(m D E C O_{i j, t}\right)$ regressions (equations (11) and (13)), we use six monthly macro-factors. There is more than one alternative variable to be tested for policy uncertainty, credit conditions, economic activity, business, and consumer sentiment in the monthly frequency case. We distinguish between global and US factors and we include them alternately to reach the preferred model according to the specification's information criteria and adjusted $R^{2}$. The monthly regressors are classified in the following macro-categories:

- Economic policy uncertainty $\left(m E P U_{t}\right)$. Two alternatives are available: the monthly US EPU $\left(E P U_{U S, t}\right)$ and the Global EPU $\left(E P U_{G, t}\right)$ from Baker, Bloom, and Davis policy uncertainty data.

- Credit conditions $\left(m C R_{t}\right)$. Four alternatives are tested: i) the global default spread, calculated as the difference between the monthly averages of Moody's BAA minus AAA global corporate bond yields $\left(B A A_{-} A A A_{G, t}\right)$, ii) the monthly average of the MOVE 1 month index $\left(M O V E_{U S, t}\right)$, iii) the Kansas City Financial Stress Index $\left(F S I_{U S, t}\right)$, a stress indicator for the US financial system built upon eleven financial market variables, and iv) the TED spread $\left(T E D_{U S, t}\right)$, a proxy for liquidity conditions and perceived credit risk in the financial system, calculated as the monthly average of the daily difference between the 3-month US libor and the 3-month US Treasury bill.

- Economic activity $\left(m E C_{t}\right)$. We test three different proxies: i) the OECD calculated Composite Leading Indicators (CLI), as the macro-factor capturing the economic activity fluctuation around its long-term potential level. All OECD countries, G7, and US CLI $\left(C L I_{O E C D, t}, C L I_{G 7, t}\right.$, and $\left.C L I_{U S, t}\right)$ are used, ii) the Federal Reserve Bank of Philadelphia Leading Index $\left(L I_{U S, t}\right)$, a predictor of the six-month US growth rate, and iii) the Chicago Fed National Activity Index $\left(N A I_{U S, t}\right)$, an index designed to gauge overall US economic activity and related inflationary pressure.

- Business sentiment $\left(B S_{t}\right)$. We use the OECD calculated Business Confidence Indicator (BCI). All OECD countries, G7, and US BCIs $\left(B C I_{O E C D, t}, B C I_{G 7, t}\right.$, and $\left.B C I_{U S, t}\right)$ are tested. Alternatively to BCI, we test the monthly average of the daily Aruoba-Diebold-Scotti $\left(A D S_{U S, t}\right)$ US Business Conditions Index (Aruoba et al., 2009), which tracks daily real business conditions based on economic data releases.

- Consumer sentiment $\left(C S_{t}\right)$. The two variables tested are: i) the University of Michigan Consumer Sentiment index $\left(C S E N T_{U S, t}\right)$, as a confidence index of US consumers, and ii) the OECD calculated Consumer Confidence Indicator (CCI) for all OECD countries $\left(C C I_{O E C D, t}\right)$.

- Geopolitical risk $\left(G P R_{t}\right)$. We use the global Geopolitical Risk index $\left(G P R_{G, t}\right)$ of Caldara and Iacoviello (2018). 
Figures 11-16 present our monthly dataset graphs. Higher equicorrelations around the global crisis (Fig. 11) are associated with higher uncertainty, lower geopolitical risks (Fig. 12) and higher credit conditions indices (Fig. 13), denoting accelerated financing costs and liquidity constraints. The increased in-crisis correlations are further related to lower levels of the economic activity proxies (Fig. 14) and a significant drop in business and consumer confidence (Fig. 15 and 16). Our graphical inspection is consistent with our main findings from the correlations regression analysis, where higher cross-asset correlations coincide mostly with poor economic fundamentals, estimating a positive sign for uncertainty and credit conditions coefficients and a negative sign for economic activity, business, and consumer sentiment, and geopolitical risk parameters.
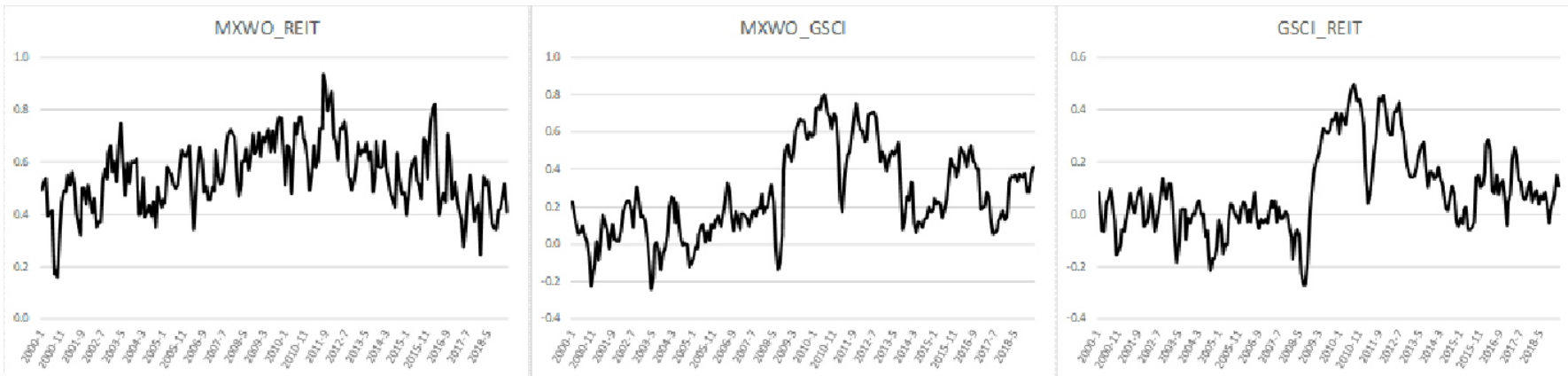

Figure 11. Monthly Dynamic Equicorrelations
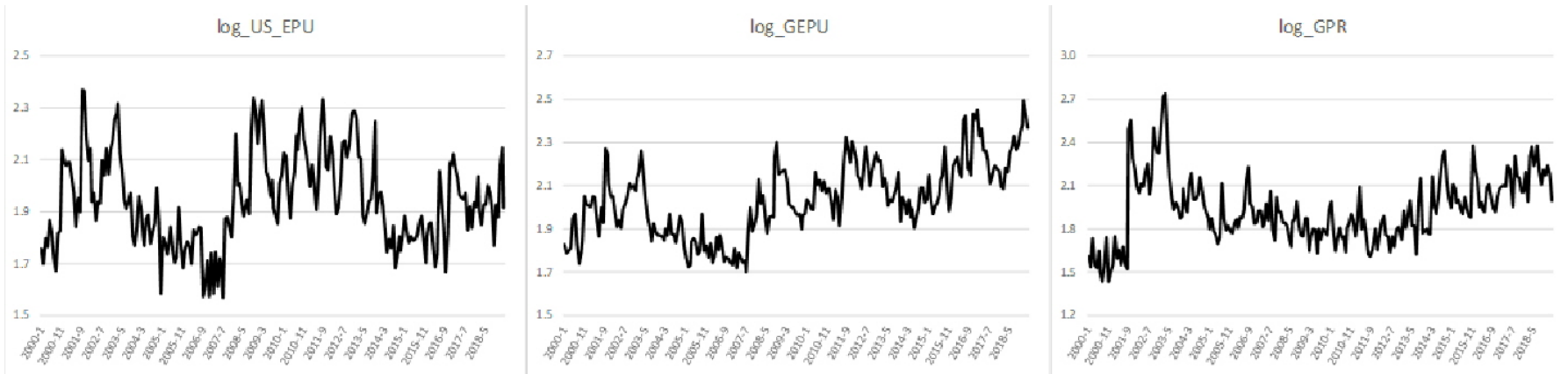

Figure 12. Monthly US EPU, Global EPU \& Geopolitical Risk Index 


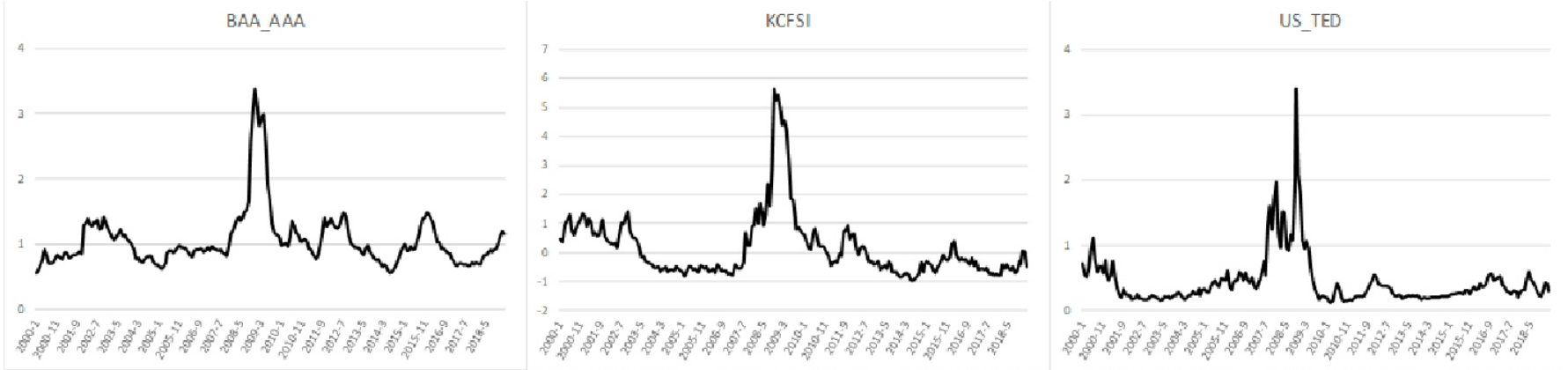

Figure 13. Moody's BAA-AAA spread, Kansas City Financial Stress Index \& US TED spread

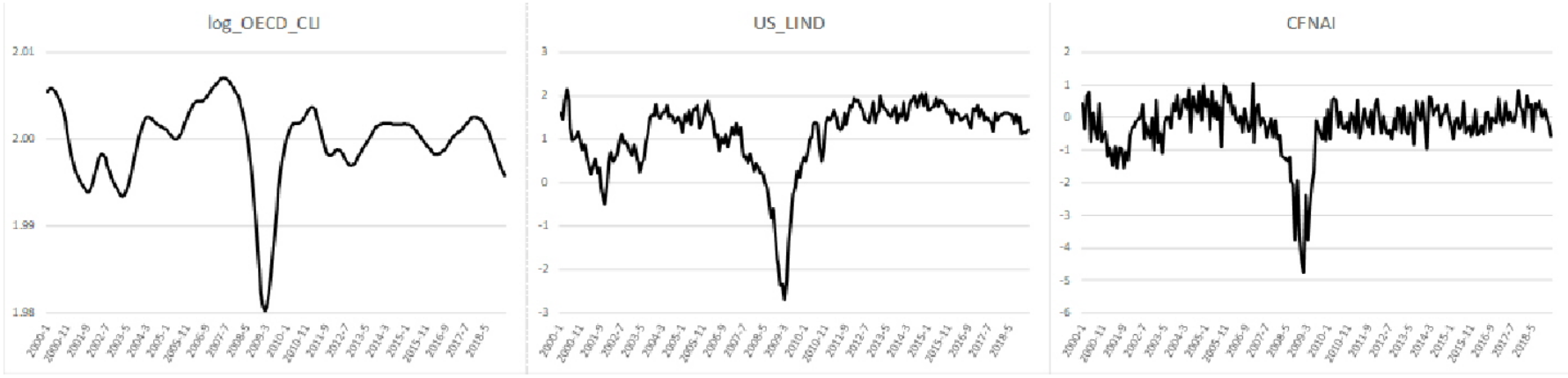

Figure 14. OECD countries CLI, Philadelphia Fed Leading Index \& Chicago Fed National Activity Index

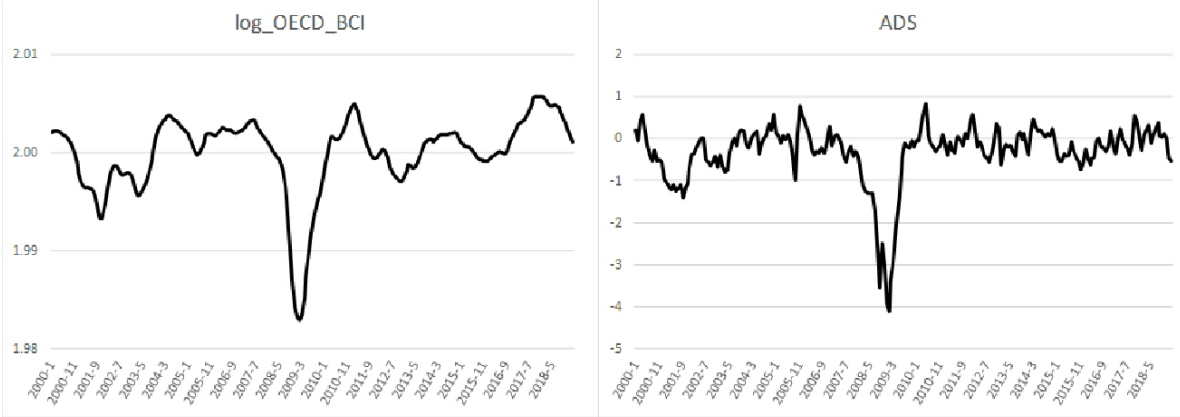

Figure 15. OECD countries BCI \& ADS Business Conditions Index 


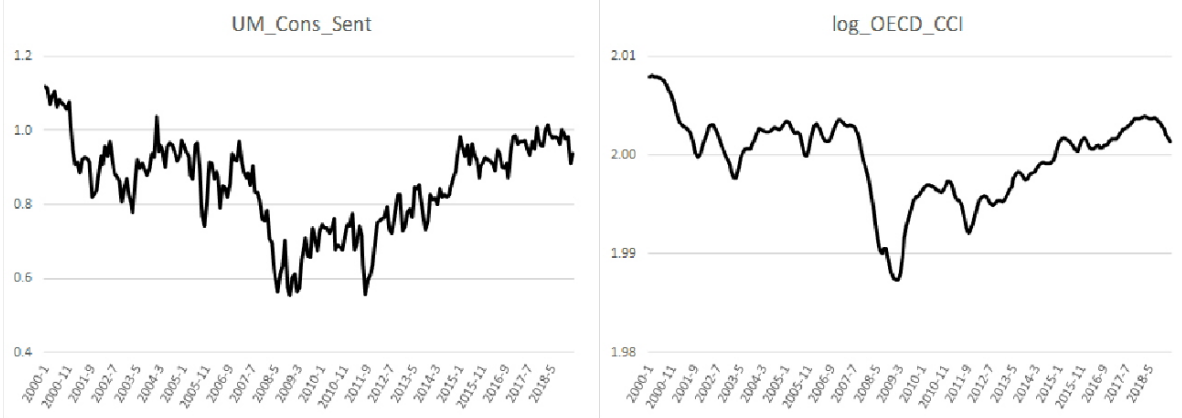

Figure 16. University of Michigan Consumer Sentiment Index \& OECD countries CCI

The daily and monthly macro-factors are tested in their level, log-level, first difference of levels or first difference of log-levels. For all variables, we denote the country of origin in the subscript as follows: $U S$ for the United States, $G$ for the global economy, OECD for the OECD countries, and $G 7$ for the G7 countries. Variables with $O E C D, G 7$, and $G$ subscripts are considered as global factors in contrast with variables with the $U S$ subscript, which are our US factors, representative proxies for the global economy. Macro-regressors' data are downloaded from FRED economic database (by St. Louis Federal Reserve Bank) and Thomson Reuters Datastream, except for the EPU and GPR indices available in https:// www.policyuncertainty.com and the CLI, BCI, and CCI indices from the OECD database.

\section{Estimation Results}

\subsection{The Bivariate DECO Model}

Multivariate GARCH models with time-varying correlations are essential for enhancing our understanding of the relationships between the (co-)volatilities of economic and financial time series. Thus, in this section, within the framework of the multivariate GJR-GARCH(1,1)-DECO $(1,1)$ model, we will analyze the dynamic correlations for the three benchmark indices of global equity, real estate, and commodity markets. Overall, we estimate three bivariate specifications on the daily index returns: the MXWO-REIT pair, resulting in the equities-real estate equicorrelations; the MXWO-GSCI for equities-commodities; and the GSCI-REIT for commodities-real estate. Moreover, we regress the daily correlations computed by the DECO model on daily macro-factors and, finally, the monthly averaged correlations on monthly explanatory macro-variables.

For robustness test purposes, we additionally run the mean equation with a Vector Autoregressive (VAR) specification allowing for cross effects from the other asset returns. The conditional variance equa- 
tion is also enriched with positive-signed macro-regressors (due to the GARCH non-negativity constraints, the non-negative variables used are EPU or VIX and MOVE in their log-level form), which have been shown to exacerbate returns volatility (see also the detailed study and literature on the volatility macrodrivers in Karanasos and Yfanti, 2020). The resulting dynamic equicorrelations from the augmented mean and variance specifications (VAR-GJR-GARCHX-DECO) are very similar to the ones estimated by the non-augmented multivariate GJR-GARCH-DECO model and the daily correlations analysis on the same macro-determinants gives almost identical results for the drivers of the evolution of time-varying cross-asset dependences. Therefore, we focus on the simple mean and variance structure to investigate the correlation determinants, which is the topic of the present study (results of the augmented mean and variance estimations available upon request).

Table 1 reports the bivariate models estimated for the three asset-pairs. The DECO estimation is a two-step procedure where in the first step the mean and variance equations are estimated, while the second step consists of estimating the conditional equicorrelations. Therefore, the mean and conditional variance equations of each index are identical in all bivariate specifications, where the index is included. In the conditional variance GJR specification, the asymmetry coefficient $\left(\gamma_{i}\right)$ is always positive and significant, denoting the larger contribution of negative shocks to the volatility process, with the highest $\gamma_{i}$ estimated for equities (MXWO). The commodities (GSCI) variance exhibits the highest persistence, computed as $\left(\alpha_{i}+\beta_{i}+\gamma_{i} / 2\right)$, while the highest correlation on average is observed between equities and real estate (see also Figures 4-6). Most importantly, all pairwise correlations increase significantly during the recent crisis period of 2007/08, suggesting probable contagion effects or elevated markets interdependence. Lastly, we observe that post-crisis dynamic correlations return to higher than the pre-crisis levels of the early 2000s, confirming the accelerated degree of financial markets integration. In what follows, we attempt to explain this integration process among equities, real estate, and commodities with the common economic factors that drive the dynamic cross-asset correlations computed by the bivariate DECO models of Table 1. 
Table 1. Bivariate GJR-GARCH(1,1)-DECO $(1,1)$ models

\begin{tabular}{|c|c|c|c|}
\hline \multicolumn{4}{|c|}{ Panel A: Mean Return Equation } \\
\hline$i$ & MXWO & REIT & GSCI \\
\hline$\phi_{i}$ & $\begin{array}{c}0.0248^{* * *} \\
(2.51)\end{array}$ & $\begin{array}{c}0.0604^{* * *} \\
(4.60)\end{array}$ & $\begin{array}{c}0.0035 \\
(0.20)\end{array}$ \\
\hline \multicolumn{4}{|c|}{ Panel B: Variance Equation } \\
\hline$\omega_{i}$ & $\begin{array}{c}0.0119^{* * * *} \\
(4.67)\end{array}$ & $\begin{array}{c}0.0246^{* * *} \\
(4.72)\end{array}$ & $\begin{array}{c}0.0080^{* * * *} \\
(2.04)\end{array}$ \\
\hline$\alpha_{i}$ & $\begin{array}{c}0.0093 \\
(0.91)\end{array}$ & $\begin{array}{c}0.0790^{* * *} \\
(5.41)\end{array}$ & $\begin{array}{l}0.0299^{* * *} \\
(4.24)\end{array}$ \\
\hline$\beta_{i}$ & $\begin{array}{l}0.9025^{* * *} \\
(64.90)\end{array}$ & $\begin{array}{l}0.8630^{* * *} \\
(56.01)\end{array}$ & $\begin{array}{l}0.9542^{* * *} \\
(108.6)\end{array}$ \\
\hline$\gamma_{i}$ & $\begin{array}{c}0.1423^{* * *} \\
(7.34)\end{array}$ & $\begin{array}{c}0.0858^{* * *} \\
(4.17)\end{array}$ & $\begin{array}{c}0.0253^{* * *} \\
(2.34)\end{array}$ \\
\hline $\log L$ & -5742.44 & -7200.90 & -8200.32 \\
\hline \multicolumn{4}{|c|}{ Panel C: Correlation Equation } \\
\hline$i$ & MXWO & MXWO & GSCI \\
\hline$j$ & REIT & GSCI & REIT \\
\hline$\rho_{i j}$ & $\begin{array}{c}0.5551^{* * *} \\
(19.25)\end{array}$ & $\begin{array}{c}0.2822^{* * *} \\
(2.82)\end{array}$ & $\begin{array}{c}0.1229^{* *} \\
(1.83)\end{array}$ \\
\hline$a$ & $\begin{array}{c}0.0307^{* * *} \\
(3.93)\end{array}$ & $\begin{array}{c}0.0257^{* * *} \\
(4.76)\end{array}$ & $\begin{array}{c}0.0180^{* * * *} \\
(3.23)\end{array}$ \\
\hline$b$ & $\begin{array}{c}0.9509^{* * * *} \\
(62.66)\end{array}$ & $\begin{array}{c}0.9706^{* * *} \\
(141.6)\end{array}$ & $\begin{array}{c}0.9773^{* * *} \\
(118.4)\end{array}$ \\
\hline $\log L$ & -11977.59 & -13568.10 & -15291.91 \\
\hline
\end{tabular}

Notes: The numbers in parentheses are t-statistics. ${ }^{* * *},{ }^{* *},{ }^{*}$

denote significance at the $0.05,0.10,0.15$ level, respectively.

$\log L$ denotes the $\log$ likelihood.

\subsection{Daily Equicorrelations}

Table 2 presents the estimation results of the daily correlation regressions on the US macro-variables. In the tables thereafter we report the variables proxying each macro-effect of equations (10) and (11). For example, the economic activity $\left(E C_{t-n}\right)$ is captured, here, by the first lag of the first difference of the US yield curve slope $\left(\Delta Y C s l_{U S, t-1}\right)$. Since the US economy is the world's largest economy, the daily US factors are considered as global proxies for our correlation pairs of global benchmark equity, real estate, and commodity indices. We choose to present the two statistically most preferred regression specifications for each correlation series, where all macro-regressors are jointly significant with a contemporaneous or causal (first lag) effect on the dependent variable. All three correlation pairs receive a positive effect from 
economic policy uncertainty, financial markets uncertainty, and turbulence in the credit channel, and a negative impact from the economic activity proxy.

The US EPU variable is tested in its log-level and first difference of log-levels transformation and is estimated significant in both forms with a contemporaneous relation to equities-real estate and a causal effect on the two commodity pairs. Higher policy uncertainty levels and growth rates mean elevated cross-asset correlations, in accordance with Fang et al. (2018b), who reveal the US EPU positive impact on stock-oil dynamic correlations. The other three macro-proxies are significant in their first lag only, implying a causal relation to correlations. The financial uncertainty rise proxied by the growth rate of the S\&P500 'fear' index, VIX, drives correlations upwards. However, in Yang et al. (2012) the VIX coefficient is insignificant, contrary to our findings, where VIX growth rate is highly significant. The credit conditions factor, denoting the turbulence in the credit market, is mostly included in the log-level first lag of the MOVE index (the implied volatility of the US government bond market), and only in the case of equitiesreal estate is the first difference of log-levels significant. Given that the credit variable's sign is always positive, we prove that higher credit turbulence, inducing tighter credit conditions, is connected with increased correlations. Finally, the yield curve slope (in level or first difference form) coefficient is always negative, signifying that a lower level or growth of economic activity is associated with higher markets interdependence. In the equities-commodities pair the term spread's first difference is significant, while, for the other two pairs, both the level and first difference of the term spread are estimated significant separately in the two different specifications of each pairwise correlation. Our first results confirm Yang et al. (2012), who also find a significant positive first lag effect of the credit conditions (proxied there by the default spread of Moody's BAA over AAA corporate bonds yield) and a negative effect of the term spread on equities-real estate correlations. 
Table 2. Daily Dynamic Equicorrelations regressions on daily macro-determinants:

US EPU, Financial uncertainty, Credit conditions \& Economic activity

\begin{tabular}{|c|c|c|c|c|c|c|c|}
\hline \multirow[b]{2}{*}{$\downarrow$ Macro-drivers } & \multirow{2}{*}{$\frac{i-j \rightarrow}{\downarrow \text { Regressors }}$} & \multicolumn{2}{|c|}{ MXWO-REIT } & \multicolumn{2}{|c|}{ MXWO-GSCI } & \multicolumn{2}{|c|}{ GSCI-REIT } \\
\hline & & (1) & (2) & (1) & $(2)$ & (1) & (2) \\
\hline & $c_{0}$ & $\begin{array}{l}0.5510^{* * *} \\
(27.25)\end{array}$ & $\begin{array}{c}0.4500^{* * *} \\
(6.61)\end{array}$ & $\begin{array}{l}0.1462^{* *} \\
(1.82)\end{array}$ & $\begin{array}{c}0.1393^{* *} \\
(1.73)\end{array}$ & $\begin{array}{c}0.0930^{* * *} \\
(1.88)\end{array}$ & $\begin{array}{c}0.0762^{* *} \\
(1.63)\end{array}$ \\
\hline & $D E C O_{i j, t-1}$ & $\begin{array}{l}0.9802^{* * *} \\
(360.5)\end{array}$ & $\begin{array}{c}0.9807^{* * *} \\
(363.1)\end{array}$ & $\begin{array}{l}0.9955^{* * *} \\
(774.7)\end{array}$ & $\begin{array}{l}0.9955^{* * *} \\
(774.3)\end{array}$ & $\begin{array}{c}0.9953^{* * *} \\
(734.5)\end{array}$ & $\begin{array}{l}0.9952^{* * *} \\
(722.3)\end{array}$ \\
\hline & $\Delta E P U_{U S, t}$ & $\begin{array}{l}0.0010^{* * *} \\
(2.09)\end{array}$ & & & & & \\
\hline EPU & $\Delta E P U_{U S, t-1}$ & & & $\begin{array}{l}0.0005^{*} \\
(1.48)\end{array}$ & & & \\
\hline & $E P U_{U S, t}$ & & $\begin{array}{c}0.0042^{* * *} \\
(2.56)\end{array}$ & & & & \\
\hline & $E P U_{U S, t-1}$ & & & & $\begin{array}{l}0.0029^{* * *} \\
(2.17)\end{array}$ & $\begin{array}{l}0.0010^{* * *} \\
(2.07)\end{array}$ & $\begin{array}{c}0.0010^{* * *} \\
(1.94)\end{array}$ \\
\hline VIX & $\Delta V I X_{U S, t-1}$ & & $\begin{array}{c}0.0208^{* * *} \\
(3.59)\end{array}$ & $\begin{array}{l}0.0104^{* * *} \\
(2.24)\end{array}$ & $\begin{array}{l}0.0103^{* * *} \\
(2.23)\end{array}$ & $\begin{array}{c}0.0108^{* * *} \\
(3.12)\end{array}$ & \\
\hline Credit & $\Delta M O V E_{U S, t-1}$ & $\underset{(1.59)}{0.0145^{*}}$ & & & & & \\
\hline Conditions & $M O V E_{U S, t-1}$ & & $\begin{array}{l}0.0599^{* *} \\
(1.73)\end{array}$ & $\begin{array}{l}0.0641^{* * *} \\
(2.57)\end{array}$ & $\begin{array}{l}0.0648^{* * *} \\
(2.60)\end{array}$ & $\begin{array}{l}0.0149^{*} \\
(1.49)\end{array}$ & $\begin{array}{c}0.0162^{*} \\
(1.54)\end{array}$ \\
\hline Economic & $\Delta Y C s l_{U S, t-1}$ & $\begin{array}{c}-0.0105^{* * *} \\
(-2.23)\end{array}$ & & $\begin{array}{c}-0.0060^{*} \\
(-1.52)\end{array}$ & $\begin{array}{c}-0.0058^{*} \\
(-1.48)\end{array}$ & & $\begin{array}{c}-0.0087^{* * *} \\
(-3.06)\end{array}$ \\
\hline Activity & $Y C s l_{U S, t-1}$ & & $\begin{array}{c}-0.0120^{* *} \\
(-1.66)\end{array}$ & & & $\begin{array}{c}-0.0086^{* *} \\
(-1.76)\end{array}$ & \\
\hline $\mathrm{AIC}$ & & -4.3310 & -4.3380 & -4.7133 & -4.7139 & -5.4033 & -5.3996 \\
\hline $\mathrm{BIC}$ & & -4.3242 & -4.3299 & -4.7052 & -4.7058 & -5.3952 & -5.3929 \\
\hline$\overline{R^{2}}$ & & 0.9602 & 0.9605 & 0.9908 & 0.9908 & 0.9903 & 0.9903 \\
\hline
\end{tabular}

Notes:

The numbers in parentheses are t-statistics. ${ }^{* * *},{ }^{* *},{ }^{*}$ denote significance at the $0.05,0.10,0.15$ level, respectively.

$\bar{R}^{2}$ is the adjusted $R^{2}$. AIC and BIC are the Akaike and the Schwartz Information Criteria, respectively.

Non-negative variables beginning with $\Delta$ are the first difference of the respective index log-level (e.g. EPU, VIX, MOVE).

$\Delta$ denotes the first difference of the level of the index, for variables taking negative values (e.g. Yield Curve slope). 


\subsection{Monthly Equicorrelations}

We, further, calculate three monthly correlation series out of the monthly averages of the daily equicorrelations to regress them on monthly economic proxies. Therefore, we use both global and US factors either separately or mixed in the various specifications we statistically prefer. Apart from EPU, credit, and economic activity proxies, we additionally use business / consumer sentiment and geopolitical risk indices, while we ignore the VIX effect in the monthly models. Tables 3,4 , and 5 present our monthly results, where, for the equities-real estate pair, we estimate models with global factors separately from those with US factors. For the other two pairs, we present global and US factors both separately and mixed in the same specification. The monthly regression results are consistent with our daily findings, providing evidence of the positive effect of policy uncertainty and credit conditions across all asset combinations, and the negative effect of economic activity proxies, in accordance with Fang et al. (2018b) and Yang et al. (2012), as well.

Regarding the additional factors tested in the monthly context, we witness the significance and negative sign of the business confidence coefficients in the three correlation pairs, while the consumer confidence parameter is negative and significant only in the equities-real estate regressions. The negative sign of confidence indicators is absolutely expected given the positive sign we estimate for the opposite sentiment, which is uncertainty through EPU and VIX. As confidence drops and uncertainty rises, correlations become higher. More interestingly, the global geopolitical risk index is found significant only in the two correlation combinations of commodities (with equities -MXWO \& GSCI- and real estate-GSCI \& REIT). We reach an intriguing and novel result for the macro-finance literature: Higher geopolitical risk means lower correlation of the commodity market with the other two risky assets, while equities-real estate correlations are not affected by the geopolitical proxy. This finding contradicts a reasonable expectation that geopolitical tensions often inducing or urging overall uncertainty would increase correlations.

Our first monthly estimations display, Table 3, reports the equities-real estate monthly correlation drivers. Within the global factors, global EPU and default spread (for the credit channel) growth rate coefficients are always positive, exacerbating correlations contemporaneously. We further estimate the OECD calculated CLI index for economic activity level, BCI and CCI indices for business and consumer confidence growth with a negative causal effect. In the US factors specifications, US EPU replaces global EPU, with results confirming our main finding that policy uncertainty increases all correlations of the assets under investigation in the present study. Notwithstanding that equities-real estate-commodities correlations evolution receives a positive increment from EPU, equities-bonds correlation studies (see, for example, Skintzi, 2019, and Li et al., 2015) consistently estimate a negative sign for uncertainty proxies, justified by the flight-to-quality hypothesis. The case of bonds is different from the risky assets we explore 
here due to the fact that bonds inclusion in a multi-asset portfolio often plays the safe-haven role in times of elevated uncertainty. Regarding the credit conditions, we find a significant causal effect of either the Kansas City Financial Stress Index or the monthly average of MOVE with the expected signs. Finally, the first lag of the Chicago Fed National Activity Index is used instead of CLI for economic activity, the ADS index as an alternative to BCI for business conditions, and the lagged University of Michigan Consumer Sentiment instead of CCI. 
Table 3. Monthly Equities-Real estate (MXWO-REIT) Dynamic Equicorrelations regressions

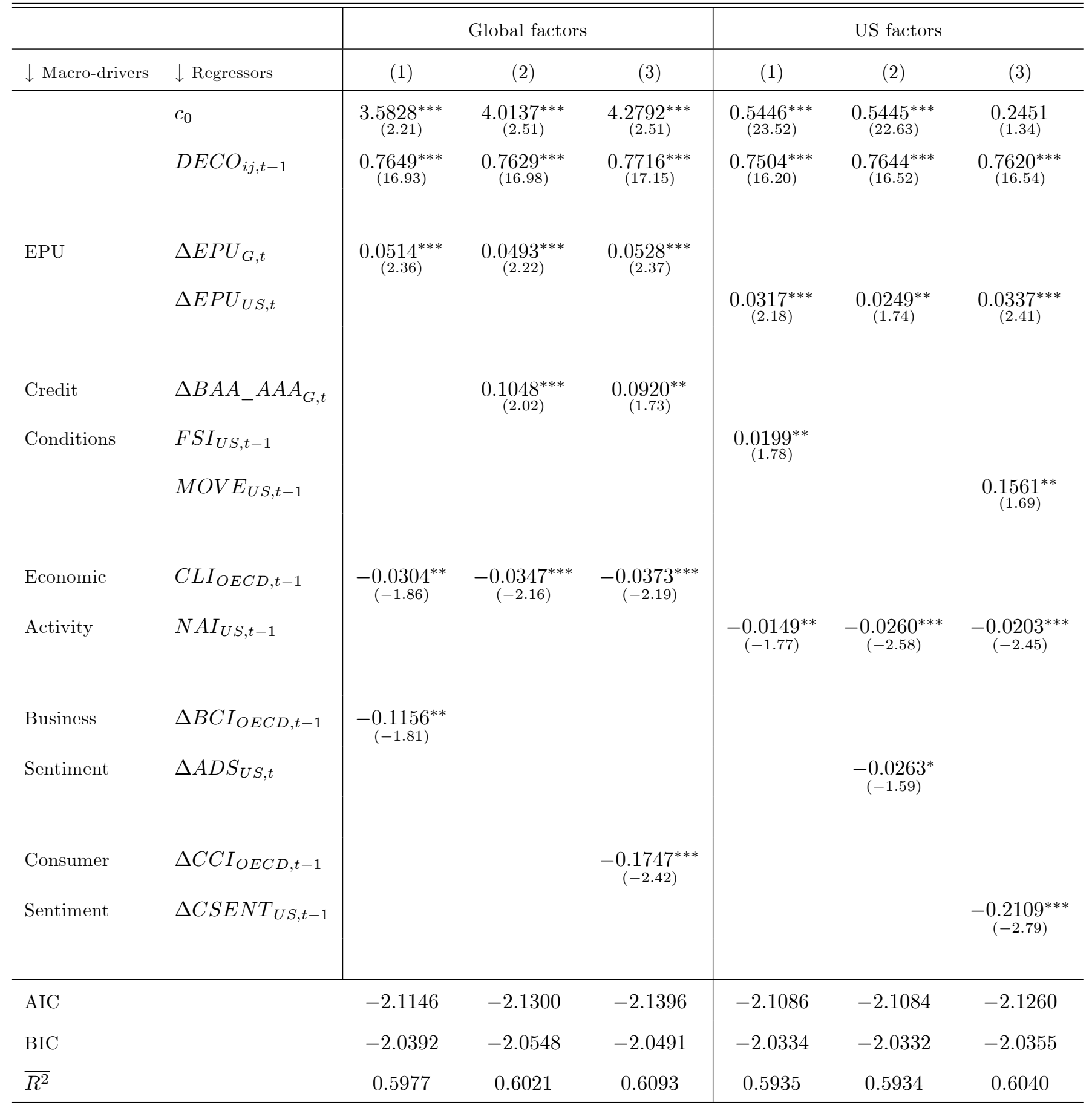

Notes: See Notes in Table 2.

The second monthly results summary, Table 4, presents the monthly equities-commodities correlations regression results. We prefer two global factors specifications and another two with both global and US macro-determinants. Global EPU and geopolitical risk are common proxies of policy uncertainty 
and geopolitical tensions, respectively, across all models. Moody's corporate bonds spread for credit conditions is highly significant in the global context and G7 countries' CLI is preferred for the overall economic activity variable. Significant US factors include the National Activity and Financial Stress indices, similarly to the equities-real estate pair, while the BCI for US firms proxying business confidence is used here, contrary to the ADS index used in equities-real estate correlations explained by US factors. In the equities-commodities correlations, we observe the same sign effects from our main macro-determinants as in MXWO-REIT monthly results (Table 3), but without the consumer confidence effect and with the novelty, here, of the significant geopolitical risk's negative impact across all four alternative specifications. 
Table 4. Monthly Equities-Commodities (MXWO-GSCI) Dynamic Equicorrelations regressions

\begin{tabular}{|c|c|c|c|c|c|}
\hline \multirow[b]{2}{*}{$\downarrow$ Macro-drivers } & \multirow[b]{2}{*}{$\downarrow$ Regressors } & \multicolumn{2}{|c|}{ Global factors } & \multicolumn{2}{|c|}{ Global \& US factors } \\
\hline & & (1) & (2) & (1) & (2) \\
\hline & $c_{0}$ & $\begin{array}{c}5.3112^{* *} \\
(1.65)\end{array}$ & $\underset{(1.61)}{4.7614^{*}}$ & $\begin{array}{c}0.2770^{* * *} \\
(3.38)\end{array}$ & $\begin{array}{l}0.2893^{* * * *} \\
(3.37)\end{array}$ \\
\hline & $D E C O_{i j, t-1}$ & $\begin{array}{c}0.9341^{* * *} \\
(41.01)\end{array}$ & $\begin{array}{c}0.9382^{* * *} \\
(41.48)\end{array}$ & $\begin{array}{c}0.9364^{* * *} \\
(39.71)\end{array}$ & $\begin{array}{c}0.9388^{* * * *} \\
(40.04)\end{array}$ \\
\hline $\mathrm{EPU}$ & $E P U_{G, t}$ & $\begin{array}{l}0.0285^{* * * *} \\
(1.94)\end{array}$ & $\underset{(1.50)}{0.0221^{*}}$ & $\begin{array}{c}0.0329^{* * *} \\
(2.00)\end{array}$ & $\begin{array}{c}0.0265^{* *} \\
(1.65)\end{array}$ \\
\hline Credit & $\triangle B A A_{-} A A A_{G, t-1}$ & $\begin{array}{l}0.0719^{* * *} \\
(2.02)\end{array}$ & & & \\
\hline Conditions & $F S I_{U S, t-1}$ & & & $\begin{array}{l}0.0452^{* * *} \\
(2.52)\end{array}$ & $\begin{array}{l}0.0455^{* * *} \\
(2.55)\end{array}$ \\
\hline Economic & $C L I_{G 7, t-1}$ & $\begin{array}{c}-0.0504^{*} \\
(-1.56)\end{array}$ & $\begin{array}{c}-0.0447^{*} \\
(-1.52)\end{array}$ & & \\
\hline Activity & $\Delta N A I_{U S, t-1}$ & & & $\begin{array}{c}-0.0074^{*} \\
(-1.51)\end{array}$ & $\begin{array}{c}-0.0076^{*} \\
(-1.54)\end{array}$ \\
\hline Business & $\Delta B C I_{G 7, t-1}$ & & $\begin{array}{c}-0.1893^{* * *} \\
(-2.23)\end{array}$ & & \\
\hline Sentiment & $\Delta B C I_{U S, t}$ & & & & $\begin{array}{c}-0.0664^{* *} \\
(-1.76)\end{array}$ \\
\hline GPR & $G P R_{G, t-1}$ & $\begin{array}{l}-0.0363^{* * *} \\
(-3.55)\end{array}$ & $\begin{array}{c}-0.0430^{* * *} \\
(-3.99)\end{array}$ & $\begin{array}{c}-0.0377^{* * *} \\
(-3.68)\end{array}$ & $\begin{array}{c}-0.0404^{* * *} \\
(-4.03)\end{array}$ \\
\hline AIC & & -2.2348 & -2.2508 & -2.2529 & -2.2559 \\
\hline $\mathrm{BIC}$ & & -2.1442 & -2.1603 & -2.1624 & -2.1503 \\
\hline$\overline{R^{2}}$ & & 0.8911 & 0.8928 & 0.8931 & 0.8938 \\
\hline
\end{tabular}

Notes: See Notes in Table 2.

Our third table with monthly regressions, Table 5 , reports the monthly commodities-real estate correlation dynamics analysis. We select to present four specifications with mixed global and US factors. EPU is proxied by global and US indices. The credit conditions channel is proxied by two US factors alternatively: the Financial Stress index, significant across all monthly correlations (see also Tables 3 and 4), and the TED spread, with a positive sign consistent with the credit variables used for both daily and monthly regressions. The TED spread is used as a credit risk proxy, further implying the overall liquidity conditions in the financial system. Since it computes the difference of the lending rate in the interbank 
market over the rate in the sovereign credit market, the TED spread is used to connote the direct passthrough of the financial institutions' liquidity conditions on corporate lending. For the economic activity effect, apart from CLI, we find the Philadelphia Fed Leading Index parameter negative and significant, as well. Business confidence also gives a negative sign, while consumer sentiment is insignificant and has been excluded, similarly to the first commodities pair with equities. Lastly, the geopolitical risk coefficient is negative and highly significant.

Table 5. Monthly Commodities-Real estate (GSCI-REIT) Dynamic Equicorrelations regressions

\begin{tabular}{|c|c|c|c|c|c|}
\hline \multirow[b]{2}{*}{$\downarrow$ Macro-drivers } & \multirow[b]{2}{*}{$\downarrow$ Regressors } & \multicolumn{4}{|c|}{ Global \& US factors } \\
\hline & & (1) & $(2)$ & $(3)$ & $(4)$ \\
\hline \multirow{4}{*}{ EPU } & $c_{0}$ & $\begin{array}{c}4.4961^{* * * *} \\
(2.26)\end{array}$ & $\begin{array}{c}0.1005^{* *} \\
(1.76)\end{array}$ & $\begin{array}{l}3.4879^{* * *} \\
(2.19)\end{array}$ & $\begin{array}{c}3.5779^{* * *} \\
(2.08)\end{array}$ \\
\hline & $D E C O_{i j, t-1}$ & $\begin{array}{c}0.9354^{* * *} \\
(37.82)\end{array}$ & $\begin{array}{c}0.9326^{* * *} \\
(38.60)\end{array}$ & $\begin{array}{c}0.9300^{* * *} \\
(36.50)\end{array}$ & $\begin{array}{c}0.9382^{* * *} \\
(41.02)\end{array}$ \\
\hline & $E P U_{G, t}$ & $\begin{array}{l}0.0280^{* *} \\
(1.87)\end{array}$ & & & \\
\hline & $E P U_{U S, t}$ & & $\begin{array}{c}0.0227^{* *} \\
(1.86)\end{array}$ & $\begin{array}{c}0.0170^{*} \\
(1.45)\end{array}$ & $\underset{(1.61)}{0.0196^{*}}$ \\
\hline Credit & $T E D_{U S, t-1}$ & $\begin{array}{c}0.0485^{* * *} \\
(2.39)\end{array}$ & & & \\
\hline Conditions & $F S I_{U S, t-1}$ & & $\begin{array}{l}0.0273^{* * *} \\
(2.57)\end{array}$ & $\begin{array}{c}0.0185^{* *} \\
(1.74)\end{array}$ & \\
\hline Economic & $C L I_{G 7, t-1}$ & $\begin{array}{c}-0.0444^{* * *} \\
(-2.24)\end{array}$ & & & \\
\hline \multirow[t]{2}{*}{ Activity } & $C L I_{U S, t-1}$ & & & $\begin{array}{c}-0.0340^{* * *} \\
(-2.13)\end{array}$ & \\
\hline & $\Delta L I_{U S, t-1}$ & & $\begin{array}{c}-0.0193^{* *} \\
(-1.78)\end{array}$ & & $\begin{array}{c}-0.0183^{*} \\
(-1.63)\end{array}$ \\
\hline Business Sentiment & $B C I_{U S, t-1}$ & & & & $\begin{array}{c}-0.0347^{* * *} \\
(-2.02)\end{array}$ \\
\hline GPR & $G P R_{G, t-1}$ & $\begin{array}{c}-0.0206^{* * *} \\
(-2.35)\end{array}$ & $\begin{array}{c}-0.0221^{* * *} \\
(-2.59)\end{array}$ & $\begin{array}{c}-0.0219^{* * *} \\
(-2.54)\end{array}$ & $\begin{array}{c}-0.0219^{* * *} \\
(-2.46)\end{array}$ \\
\hline $\mathrm{AIC}$ & & -2.9071 & -2.8960 & -2.8869 & -2.8894 \\
\hline $\mathrm{BIC}$ & & -2.8169 & -2.8055 & -2.7967 & -2.7988 \\
\hline$\overline{R^{2}}$ & & 0.8820 & 0.8807 & 0.8796 & 0.8799 \\
\hline
\end{tabular}

Notes: See Notes in Table 2. 
All in all, we provide sound evidence on the macro-drivers of equities, real estate, and commodities correlations evolution, consistent at both daily and monthly frequencies. Elevated cross-asset correlations are associated with higher uncertainty and tighter credit conditions, while lower correlations are related to higher economic activity and business confidence indices. Moreover, consumer confidence negatively affects the equities-real estate correlations and geopolitical risk the two commodity correlation pairs of the GSCI index with REITs and MSCI World Equities. Hence, our main finding highlights the fact that economic variables which are associated with weak economic conditions exacerbate correlations, while leading or coincident activity growth indicators mostly reduce cross-asset interdependence. Accordingly, the inflating EPU and crisis effect on the macro-factors, investigated in the following parts of our empirical analysis (Sections 5 and 6), is economically plausible since increased uncertainty and crisis are linked to economic downturns. Our results could also contribute to the financial contagion literature. Following Forbes and Rigobon (2002), contagion is characterized by the increased spillovers between different markets after a crisis shock in one market and interdependence is their high inter-linkages during all states of the economy. Given that higher correlations are mainly explained, here, by poor economic fundamentals, we can infer possible cross-asset contagion effects.

\section{The Uncertainty Effect on Correlations}

The important role of EPU, global and US-originated, on equities-real estate-commodities correlation dynamics is further explored, focusing on the indirect impact on cross-asset interdependence through the macro-factors that drive this particular interdependence. Thus, the intriguing question we raise is whether EPU exerts considerable influence not only directly on correlations evolution, but, more precisely, on the economic forces that determine the time-varying behavior of conditional equicorrelations. Our empirical results have important implications for macro-informed trading in financial markets and policymakers' financial stability concerns and systemic risk oversight. Admittedly, cross-asset correlation dynamics merit the attention of both financial analysts in portfolio optimization and risk management (diversification and hedging) and regulators in their market intervention activities (stabilization and proactive macro-prudential policies). According to our review of the flourishing research on uncertainty effects, academics have not yet covered the EPU macro-effect on cross-asset correlations and, particularly, the EPU amplifying role on the impact of financial uncertainty, credit channel, economic activity, agents' confidence, and geopolitical risk, which becomes plainly visible here through the DECO framework.

In this vein, we have already highlighted the direct positive impact, in line with Pastor and Veronesi (2013), of EPU on correlations. In this Section we investigate the EPU effect on the daily and monthly macro-drivers of dynamic equicorrelations. Table 6 reports the coefficients of the interaction terms esti- 
mated in equations (12), Panel A, and (13), Panel B. We present the uncertainty effect on each macrodeterminant as estimated through alternative restricted forms of equations (12) and (13), including each EPU effect separately (each coefficient with the superscript ${ }^{E P U}$ is estimated separately). Table 6 notation follows the notation of Tables 2-5, where we report the variables proxying each macro-effect of equations (10) and (11). For example, the EPU effect on economic activity $\left(E P U_{t-n} E C_{t-n}\right)$ is captured through the interaction term of the lagged first difference of the yield curve slope $\left(E P U_{U S, t-1} d Y C s l_{U S, t-1}\right)$ in the daily context.

All significant interaction terms are estimated with the same sign of the respective macro-effect. Intriguingly, we prove that higher policy uncertainty means a stronger effect of financial uncertainty, credit conditions, economic activity, business, and consumer sentiment, and geopolitical risk on cross-asset correlations. Since there is widespread evidence that higher uncertainty is associated with economic worsening, we further deduce the link to tighter credit conditions and reduced business and consumer confidence during business cycle's downturns, with higher financial correlations heavily affected by the uncertainty channel. In other words, EPU partly drives or explains the macro-determinants of equicorrelations, amplifying their effect.

Within the daily context (Table 6, Panel A), the financial uncertainty and credit EPU interaction terms are positive, while the economic activity terms are negative. For the commodities-real estate pair, the EPU effect on credit conditions is insignificant and, therefore, has been excluded. In the monthly frequency (Table 6, Panel B), the indirect positive effect of EPU on cross-asset interdependence is proved through the credit channel, with credit conditions interaction terms highly significant and positive. The global default spread, the US TED spread, Financial Stress Index, and MOVE exert considerable influence on monthly correlations, partly explained by EPU. In the uncertainty literature, the link between the tightening of credit conditions and uncertainty has recently been investigated by Alessandri and Mumtaz (2019), who associate the rising financing costs for firms with credit markets uncertainty. Moreover, the interaction terms of CLI are not significant, while lower economic activity, proxied by NAI and LI US indices and associated with higher policy uncertainty, raises all correlations. Turning to business confidence driven by policy uncertainty, we exclude it in the the case of commodities-real estate since the BCI interaction term is insignificant. For the other two correlation pairs with equities, both BCI and ADS reduce correlations through the uncertainty channel. The consumer sentiment's decreasing effect, applied only in the MSCI-REITs combination, is partially explained by higher EPU. Lastly, the geopolitical risk's negative impact is intensified by higher EPU for the two GSCI pairs.

All macro-determinants receive a substantial policy uncertainty effect. Overall, we demonstrate that the three cross-asset correlations are consistently exacerbated by EPU, which amplifies the influence of the other macro-drivers as well. Our leading-edge results should urge policymakers to consider and closely 
investigate both direct and side effects of an EPU shock on the co-movement of different asset markets. Further, our contribution to the EPU literature consists of the novel empirical evidence we provide on the positive direct and indirect link between daily and monthly EPU and cross-asset equicorrelations dynamics. Within the DECO framework, we, firstly, prove the EPU destabilizing impact that drives correlations higher. Secondly, we show that the macro-effects on correlations evolution are state-dependent, not only based on structural changes (see Section 6), but they are also considerably magnified under higher prevailing uncertainty conditions. Thirdly, and most interestingly from an economic perspective, tighter credit conditions, a worse economic stance, a lack of agents' confidence, and lower geopolitical risk exacerbate correlations to a degree intensified by elevated EPU. Finally, we complement the literature on EPU spillovers (see, for example, Gabauer and Gupta, 2018, Balli et al., 2017, and Klößner and Sekkel, 2014) by providing evidence of the daily and monthly uncertainty spillover effects from the US to global financial correlations. We have shown that policy uncertainty in a major economy is not confined to the country's borders but is propagated across the global markets immediately (only the contemporaneous effect and the first EPU lag have been examined in this study). 
Table 6. The EPU effect on the macro-drivers of cross-asset correlations evolution

\begin{tabular}{|c|c|c|c|c|}
\hline$\downarrow$ Macro-drivers & $\downarrow$ Interaction terms & MXWO-REIT & MXWO-GSCI & GSCI-REIT \\
\hline \multicolumn{5}{|c|}{ Panel A: Daily Dynamic Equicorrelations regressions } \\
\hline VIX & $E P U_{U S, t-1} \Delta V I X_{U S, t-1}$ & $\begin{array}{l}0.0109^{* * *} \\
(3.69)\end{array}$ & $\begin{array}{l}0.0053^{* * *} \\
(2.20)\end{array}$ & $\begin{array}{l}0.0059^{* * *} \\
(3.29)\end{array}$ \\
\hline Credit & $E P U_{U S, t-1} \Delta M O V E_{U S, t-1}$ & $\begin{array}{l}0.0075^{*} \\
(1.56)\end{array}$ & $\begin{array}{l}0.0056^{* *} \\
(1.67)\end{array}$ & \\
\hline Conditions & $E P U_{U S, t-1} M O V E_{U S, t-1}$ & & $\begin{array}{c}0.0015^{* * *} \\
(2.18)\end{array}$ & \\
\hline Economic & $E P U_{U S, t-1} \Delta Y C s l_{U S, t-1}$ & $\begin{array}{c}-0.0053^{* * *} \\
(-2.29)\end{array}$ & $\begin{array}{c}-0.0032^{*} \\
(-1.58)\end{array}$ & $\begin{array}{c}-0.0046^{* * *} \\
(-3.16)\end{array}$ \\
\hline Activity & $E P U_{U S, t-1} Y C s l_{U S, t-1}$ & & & $\begin{array}{c}-0.0021^{* * *} \\
(-3.01) \\
\end{array}$ \\
\hline \multicolumn{5}{|c|}{ Panel B: Monthly Dynamic Equicorrelations regressions } \\
\hline \multirow{6}{*}{$\begin{array}{l}\text { Credit } \\
\text { Conditions }\end{array}$} & $E P U_{G, t} \Delta B A A_{-} A A A_{G, t}$ & $\begin{array}{c}0.0466^{* *} \\
(1.84)\end{array}$ & & \\
\hline & $E P U_{G, t-1} \Delta B A A_{-} A A A_{G, t-1}$ & & $\begin{array}{l}0.0355^{* * *} \\
(2.23)\end{array}$ & \\
\hline & $E P U_{G, t-1} T E D_{U S, t-1}$ & & & $\begin{array}{l}0.0207^{* * *} \\
(2.26)\end{array}$ \\
\hline & $E P U_{G, t-1} F S I_{U S, t-1}$ & & $\begin{array}{l}0.0216^{* * *} \\
(2.67)\end{array}$ & \\
\hline & $E P U_{U S, t-1} F S I_{U S, t-1}$ & $\begin{array}{l}0.0083^{* *} \\
(1.75)\end{array}$ & & $\begin{array}{l}0.0122^{* * *} \\
(2.63)\end{array}$ \\
\hline & $E P U_{U S, t-1} M O V E_{U S, t-1}$ & $\begin{array}{c}0.0548^{* *} \\
(1.90) \\
\end{array}$ & & \\
\hline Economic & $E P U_{G, t-1} \Delta N A I_{U S, t-1}$ & & $\begin{array}{c}-0.0036^{*} \\
(-1.48)\end{array}$ & \\
\hline \multirow[t]{3}{*}{ Activity } & $E P U_{U S, t-1} N A I_{U S, t-1}$ & $\begin{array}{l}-0.0105^{* * *} \\
(-2.56)\end{array}$ & & \\
\hline & $E P U_{U S, t-1} \Delta L I_{U S, t-1}$ & & & $\begin{array}{c}-0.0093^{* *} \\
(-1.67) \\
\end{array}$ \\
\hline & $E P U_{G, t-1} \Delta B C I_{O E C D, t-1}$ & $\begin{array}{c}-0.0501^{* *} \\
(-1.65)\end{array}$ & & \\
\hline Business & $E P U_{G, t-1} \Delta B C I_{G 7, t-1}$ & & $\begin{array}{c}-0.0968^{* * *} \\
(-2.31)\end{array}$ & \\
\hline \multirow[t]{2}{*}{ Sentiment } & $E P U_{G, t} \Delta B C I_{U S, t}$ & & $\begin{array}{l}-0.0355^{* * *} \\
(-1.97)\end{array}$ & \\
\hline & $E P U_{U S, t} \Delta A D S_{U S, t}$ & $\begin{array}{c}-0.0132^{* *} \\
(-1.70) \\
\end{array}$ & & \\
\hline Consumer & $E P U_{G, t-1} \Delta C C I_{O E C D, t-1}$ & $\begin{array}{c}-0.0866^{* * *} \\
(-2.43)\end{array}$ & & \\
\hline Sentiment & $E P U_{U S, t-1} \Delta C S E N T_{U S, t-1}$ & $\begin{array}{c}-0.1076^{* * *} \\
(-2.91) \\
\end{array}$ & & \\
\hline Geopolitical & $E P U_{G, t-1} G P R_{G, t-1}$ & & $\begin{array}{c}-0.0181^{* * *} \\
(-3.99)\end{array}$ & $\begin{array}{c}-0.0089^{* * *} \\
(-2.20)\end{array}$ \\
\hline Risk & $E P U_{U S, t-1} G P R_{G, t-1}$ & & & $\begin{array}{c}-0.0103^{* * *} \\
(-2.60) \\
\end{array}$ \\
\hline
\end{tabular}

Notes: The numbers in parentheses are t-statistics. ${ }^{* * *},{ }^{* *},{ }^{*}$ denote significance at the $0.05,0.10,0.15$

level, respectively. 


\section{The Crisis Effect}

Following the regression analysis of the macro-determinants of the equities-real estate-commodities correlations evolution, in this Section we investigate the impact of structural changes (detected in the equicorrelations time series used as dependent variables) on the macro-regressors. The time-varying behavior of the explanatory variables' parameters can be significant around a financial crisis break, in particular, indicative of the crisis effects on the correlation pattern. We incorporate structural break dummies in the monthly and daily specifications (eq. (10) and (11)). The structural breaks of the three daily correlation series are identified, and, focusing mainly on the recent global financial crisis, we study their impact on the correlations evolution framework.

The methodology in Bai and Perron $(1998,2003 \mathrm{a}, \mathrm{b})$ is employed to test for structural breaks. They address the problem of testing for multiple structural changes in a least squares context and under very general conditions on the data and the errors. In addition to testing for the presence of breaks, these statistics identify the number and location of multiple breaks. So, we identify the structural breaks in equicorrelations with the Bai and Perron methodology (see Table 7, Figures 17 and 18). We use the breaks identified in order to build the slope dummies for the various macro-parameters. One break date for the recent global financial crisis of 2007/08 (GFC) is detected, so we can focus on the crisis effect. We also detect one break date after the crisis, whose effect is not included in the regression analysis of the correlations' determinants since the slope dummies corresponding to the second break are insignificant in most cases.

Table 7. The break dates of dynamic equicorrelations

\begin{tabular}{lccc}
\hline \hline & MXWO-REIT & MXWO-GSCI & GSCI-REIT \\
\cline { 2 - 4 } $1^{\text {st }}$ Break & $27 / 02 / 2007$ & $02 / 10 / 2008$ & $24 / 11 / 2008$ \\
$2^{\text {nd }}$ Break & $20 / 04 / 2016$ & $15 / 08 / 2013$ & $09 / 10 / 2012$ \\
\hline Notes: Bai \& Perron breaks identification: Results selected \\
from the repartition procedure for 5\% significance level with \\
5 maximum number of breaks and 0.05 trimming parameter.
\end{tabular}




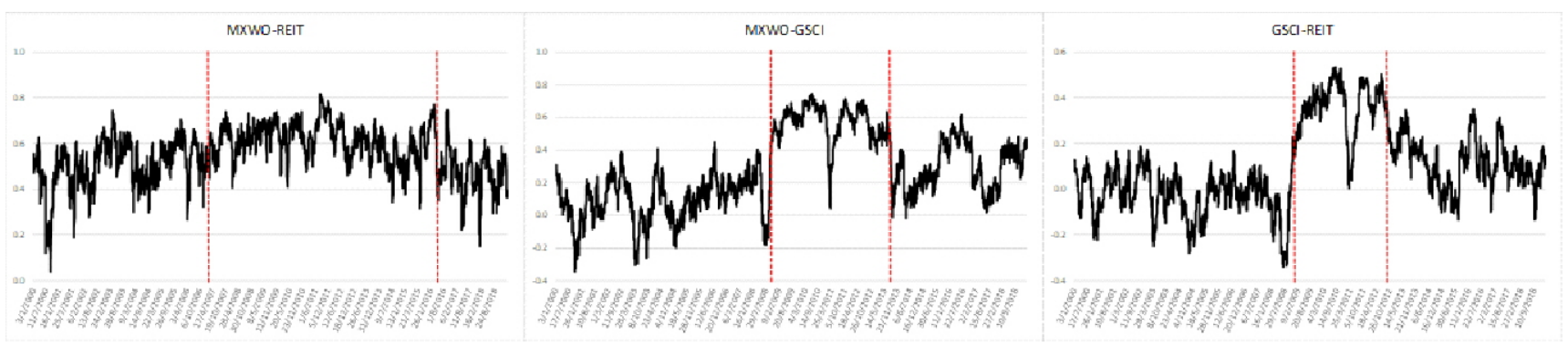

Figure 17. Daily Dynamic Equicorrelations with structural breaks

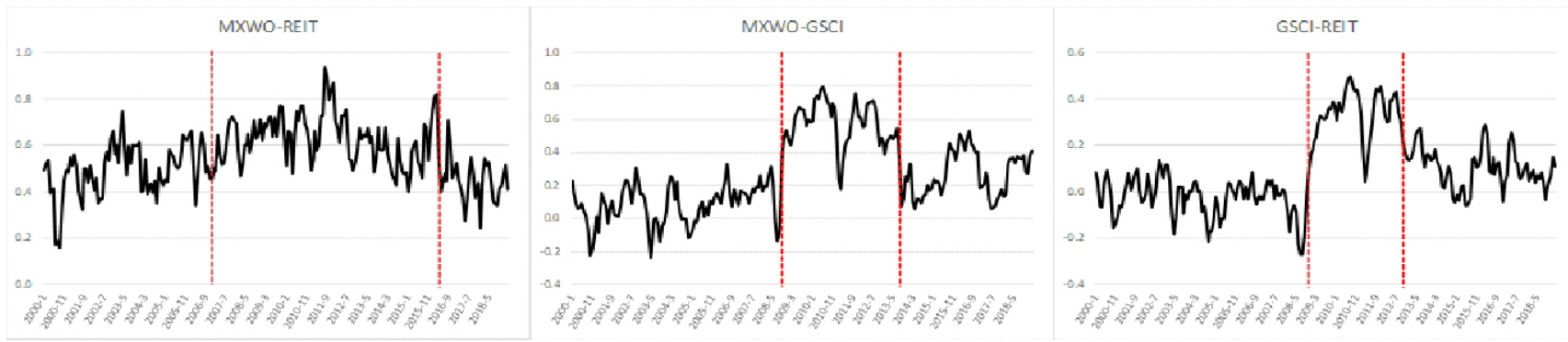

Figure 18. Monthly Dynamic Equicorrelations with structural breaks

We re-estimate the two basic correlation regressions (eq. (10) and (11)) for each asset-pair by adding the macro-variables' slope dummies for the first break. First, the dummy variable of the GFC structural break is defined as follows: $D_{G F C, t}=0$, if $t<T$ and $D_{G F C, t}=1$, if $t \geqslant T$, with $T=$ the $1^{\text {st }}$ break date of each equicorrelation series. Second, we multiply the $D_{G F C, t}$ dummy with the macro-variables to construct the slope dummies for the respective macro-effect. In the monthly context, the dummy variable $m D_{G F C, t}$ is calculated in the same way as in the daily case, with $T$ referring to the month of the $1^{\text {st }}$ break date. Thereafter, the daily and monthly regression equations incorporate the structural changes of the dynamic equicorrelation time series:

$$
\begin{aligned}
D E C O_{i j, t}= & c_{0}+c_{1} D E C O_{i j, t-1}+c_{2} E P U_{t-n}+c_{2}^{G F C} D_{G F C, t-n} E P U_{t-n}+c_{3} F U_{t-n} \\
& +c_{3}^{G F C} D_{G F C, t-n} F U_{t-n}+c_{4} C R_{t-n}+c_{4}^{G F C} D_{G F C, t-n} C R_{t-n} \\
& +c_{5} E C_{t-n}+c_{5}^{G F C} D_{G F C, t-n} E C_{t-n}+u_{i j, t},
\end{aligned}
$$




$$
\begin{aligned}
m D E C O_{i j, t}= & z_{0}+z_{1} m D E C O_{i j, t-1}+z_{2} m E P U_{t-n}+z_{2}^{G F C} m D_{G F C, t-n} m E P U_{t-n} \\
& +z_{3} m C R_{t-n}+z_{3}^{G F C} m D_{G F C, t-n} m C R_{t-n}+z_{4} m E C_{t-n}+z_{4}^{G F C} m D_{G F C, t-n} m E C_{t-n} \\
& +z_{5} B S_{t-n}+z_{5}^{G F C} m D_{G F C, t-n} B S_{t-n}+z_{6} C S_{t-n}+z_{6}^{G F C} m D_{G F C, t-n} C S_{t-n} \\
& +z_{7} G P R_{t-n}+z_{7}^{G F C} m D_{G F C, t-n} G P R_{t-n}+U_{i j, t} .
\end{aligned}
$$

The crisis impact on the time-varying macro-effects is captured by the slope dummies' coefficients with the ${ }^{G F C}$ superscript. In Table 8, we present the crisis effect on each macro-determinant as estimated through alternative restricted forms of equations (14) and (15) by including each slope dummy separately. Table 8 notation follows Table 6, where we report the variables proxying each macro-effect of equations (14) and (15). For example, the crisis effect on economic activity $\left(D_{G F C, t-n} E C_{t-n}\right)$ is captured through the slope dummy of the lagged first difference of the yield curve slope $\left(D_{G F C, t-1} \Delta Y C s l_{U S, t-1}\right)$ in the daily context.

We first report the estimation results of the daily regression equation (14) with the crisis break influence on the time-varying behavior of the macro-effects (Table 8, Panel A). In the post-crisis period, the four macro-factors exert a more profound influence on dynamic correlations. The EPU, VIX, and credit conditions effects become more positive and the economic activity effect more negative. The crisis adds an increment in absolute terms across all macro-parameters, apart from the EPU crisis dummy in the equities-commodities pair, where it is not significant and, therefore, has been excluded. Turning to the monthly results (Table 8, Panel B), the higher EPU and tighter credit conditions growth and level further exacerbate correlations following the crisis break across all asset pairs. Lower economic activity and consumer confidence increase cross-asset interdependence, with the additional crisis increment only in the equities-real estate combination. The negative impact of business sentiment is intensified during the crisis for the two equities correlation pairs, while, in the commodities-real estate case, we estimate a small positive coefficient for the US BCI slope dummy, which reduces the negative in-crisis BCI effect. Lastly, the geopolitical risk influence is significantly eased post-crisis, given that the respective dummy receives a positive sign, opposite to the negative relation of GPR, with the two commodities correlations estimated for the whole sample period. 
Table 8. The crisis effect on the macro-drivers of cross-asset correlations evolution

\begin{tabular}{|c|c|c|c|c|}
\hline$\downarrow$ Macro-drivers & $\downarrow$ Crisis slope dummies & MXWO-REIT & MXWO-GSCI & GSCI-REIT \\
\hline \multicolumn{5}{|c|}{ Panel A: Daily Dynamic Equicorrelations regressions } \\
\hline \multirow{3}{*}{ EPU } & $D_{G F C, t} \Delta E P U_{U S, t}$ & $\underset{(1.52)}{0.0010^{*}}$ & & \multirow[b]{3}{*}{$\begin{array}{c}0.0013^{* *} \\
(1.84)\end{array}$} \\
\hline & $D_{G F C, t} E P U_{U S, t}$ & $\begin{array}{l}0.0050^{* * *} \\
(2.25)\end{array}$ & & \\
\hline & $D_{G F C, t-1} E P U_{U S, t-1}$ & & & \\
\hline VIX & $D_{G F C, t-1} \Delta V I X_{U S, t-1}$ & $\begin{array}{l}0.0270^{* * *} \\
(3.82)\end{array}$ & $\begin{array}{c}0.0164^{* * *} \\
(2.77)\end{array}$ & $\begin{array}{c}0.0125^{* * *} \\
(2.86)\end{array}$ \\
\hline Credit & $D_{G F C, t-1} \Delta M O V E_{U S, t-1}$ & $\begin{array}{l}0.0229^{* *} \\
(1.78)\end{array}$ & & \\
\hline Conditions & $D_{G F C, t-1} M O V E_{U S, t-1}$ & $\begin{array}{l}0.0863^{* * *} \\
(6.81)\end{array}$ & $\begin{array}{c}0.0129^{* * *} \\
(2.57)\end{array}$ & $\begin{array}{c}0.0160^{* * *} \\
(4.61)\end{array}$ \\
\hline Economic & $D_{G F C, t-1} \Delta Y C s l_{U S, t-1}$ & $\begin{array}{c}-0.0170^{* * *} \\
(-2.92)\end{array}$ & $\begin{array}{c}-0.0107^{* *} \\
(-1.70)\end{array}$ & $\begin{array}{c}-0.0179^{* * *} \\
(-3.75)\end{array}$ \\
\hline Activity & $D_{G F C, t-1} Y C s l_{U S, t-1}$ & $\begin{array}{c}-0.0205^{* * *} \\
(-2.02) \\
\end{array}$ & & \\
\hline \multicolumn{5}{|c|}{ Panel B: Monthly Dynamic Equicorrelations regressions } \\
\hline \multirow{4}{*}{$\mathrm{EPU}$} & $D_{G F C, t} \Delta E P U_{G, t}$ & $\begin{array}{l}0.0598^{* * *} \\
(2.26)\end{array}$ & & \multirow{3}{*}{$\begin{array}{c}0.0878^{* * *} \\
(4.43)\end{array}$} \\
\hline & $D_{G F C, t} E P U_{G, t}$ & & $\begin{array}{l}0.0521^{* * *} \\
(2.49)\end{array}$ & \\
\hline & $D_{G F C, t} \Delta E P U_{U S, t}$ & $\begin{array}{l}0.0295^{*} \\
(1.50)\end{array}$ & & \\
\hline & $D_{G F C, t} E P U_{U S, t}$ & & & $\begin{array}{c}0.0308^{* * *} \\
(2.24) \\
\end{array}$ \\
\hline & $D_{G F C, t} \Delta B A A_{-} A A A_{G, t}$ & $\begin{array}{l}0.1075^{* *} \\
(1.65)\end{array}$ & & \\
\hline Credit & $D_{G F C, t-1} \Delta B A A_{-} A A A_{G, t-1}$ & & $\begin{array}{l}0.1024^{* * *} \\
(2.96)\end{array}$ & \\
\hline \multirow[t]{2}{*}{ Conditions } & $D_{G F C, t-1} F S I_{U S, t-1}$ & $\begin{array}{c}0.0163^{*} \\
(1.54)\end{array}$ & $\begin{array}{l}0.0305^{* * *} \\
(5.05)\end{array}$ & $\begin{array}{c}0.0146^{* *} \\
(1.66)\end{array}$ \\
\hline & $D_{G F C, t-1} M O V E_{U S, t-1}$ & $\begin{array}{l}0.0412^{* * *} \\
(2.14)\end{array}$ & & \\
\hline \multirow[t]{2}{*}{$\begin{array}{l}\text { Economic } \\
\text { Activity }\end{array}$} & $D_{G F C, t-1} N A I_{U S, t-1}$ & $\begin{array}{c}-0.0276^{* * *} \\
(-2.54)\end{array}$ & & \\
\hline & $D_{G F C, t-1} \Delta B C I_{O E C D, t-1}$ & $\begin{array}{c}-0.1193^{*} \\
(-1.51)\end{array}$ & & \\
\hline Business & $D_{G F C, t-1} \Delta B C I_{G 7, t-1}$ & & $\begin{array}{c}-0.1597^{* * *} \\
(-2.66)\end{array}$ & \\
\hline \multirow[t]{2}{*}{ Sentiment } & $D_{G F C, t} \Delta B C I_{U S, t}$ & & $\begin{array}{c}-0.1266^{* * *} \\
(-2.31)\end{array}$ & \\
\hline & $D_{G F C, t-1} \Delta B C I_{U S, t-1}$ & & & $\begin{array}{c}0.0009^{* *} \\
(1.85)\end{array}$ \\
\hline Consumer & $D_{G F C, t-1} \Delta C C I_{O E C D, t-1}$ & $\begin{array}{c}-0.1888^{* * *} \\
(-1.94)\end{array}$ & & \\
\hline Sentiment & $D_{G F C, t-1} \Delta C S E N T_{U S, t-1}$ & $\begin{array}{c}-0.1393^{*} \\
(-1.59) \\
\end{array}$ & & \\
\hline $\begin{array}{l}\text { Geopolitical } \\
\text { Risk }\end{array}$ & $D_{G F C, t-1} G P R_{G, t-1}$ & & $\begin{array}{c}0.0383^{* *} \\
(1.74)\end{array}$ & $\begin{array}{l}0.0393^{* * *} \\
(2.55)\end{array}$ \\
\hline
\end{tabular}

Notes: See Notes in Table 6 . 
All in all, considering the GFC break we provide sound evidence that the crisis mostly intensifies the macro-effects, driving correlations either lower or higher, consistently with the EPU incremental effect on VIX, credit, economic activity, confidence, and GPR (see Section 5). Higher uncertainty and tighter credit conditions proxies receive a substantial boost from the crisis break in increasing correlations, while lower economic activity and agents' confidence exacerbate correlations during the crisis. The sole exception to the overall inflating impact of the GFC break on the macro-drivers of dynamic equicorrelations is the geopolitical factor, whose negative impact is alleviated during the crisis period, contrary to the EPU effect, which intensifies the GPR negative impact.

Our breaks and EPU analyses give clear evidence that there is significant contagion between the different asset markets. The GFC slope dummy estimated coefficients show that the macro-drivers' impact on correlations' increase is partly attributed to the economic crash of the crisis advent. Hence, apart from the effect on correlations from common factors in normal times, we observe the distinct contagion effect of the same factors during the crisis (breaks analysis) or higher EPU levels connected to turmoil periods (EPU analysis in Section 5), in line with empirical results for VIX as a financial contagion driver in Akay et al. (2013) and Batten et al. (2019), among others.

\section{Conclusions}

One of the intriguing questions arising in the research field of conditional correlation dynamics is what explains the evolution of the correlation pattern and, especially, how cross-asset interlinkages respond to the macro-factors common for global equity, real estate, and commodity markets. We have therefore identified the global and US macroeconomic determinants of the dynamic correlations between three asset markets: equities, real estate, and commodities. Conditional equicorrelations were first computed through the GJR-GARCH-DECO model and, then, regressed on the macro-financial proxies of economic policy and financial uncertainty, credit conditions, economic activity, business and consumer confidence, and geopolitical risk. Thus, we have explored the exposure of correlations to each common factor, concluding that elevated cross-asset correlations are mainly associated with poor economic fundamentals, in accordance with the contagion literature. In particular, our results, consistent across both daily and monthly frequencies, suggest that increased correlations are related to higher uncertainty and tighter credit conditions, while lower correlations concur with stronger economic activity and business confidence. Consumer confidence is significant only for the equities-real estate correlations with a negative sign, and, more interestingly, higher geopolitical risk decreases the two commodity correlations with equities and real estate, leaving the equities-real estate pair without geopolitical repercussions.

Moreover, scientific emphasis has shifted to textual-mining and machine-learning techniques in the 
use of agents' economic uncertainty measurement from real-time news coverage, altering the way scholars view and conduct empirical macro-financial research. Against this background, we further focused on the news-based EPU index as a driving force of the asset markets integration process. In principle, our analysis explores how the significant macro-factors' effect on cross-asset correlations responds to the EPU dynamics. In this vein, we conclude that EPU magnifies all macro-effects across all correlations. Our empirical evidence reveals that higher financial markets uncertainty, tighter credit conditions, worse economic stance, a lack of agents' confidence, and lower geopolitical risk exacerbate correlations to a degree intensified by elevated EPU. Lastly, we investigated the global financial crisis effect on the time-varying impact of the correlations' macro-drivers, which become inter-asset contagion transmitters, as well. The crisis structural break amplifies the influence that all determinants exert on correlations evolution apart from the geopolitical risk upshot, which is alleviated after the crisis advent.

Our empirical findings on the driving forces of the nexus between global equity, real estate, and commodity markets are of paramount importance for policymaking, investment and risk management practice. Policymakers and market players should consider the economic factors behind cross-market correlations in the process of devising drastic policies, enforcing financial system's regulations, deciding on asset allocation, hedging strategies, and investment projects. Higher correlations during weaker economic conditions mean lower diversification benefits and higher risks for market practitioners. The insights we glean from the common drivers of inter-asset co-movement and contagion project important policy implications. Regulators are concerned about correlations since they represent a major barometer of the whole financial system's stability and the economy's vulnerability. Contagion risks during crisis periods should be proactively mitigated before the spillover mechanisms drive the different financial markets to a synchronous crash or harmful slowdown and systemic risk build-ups. Our results are also highly topical for both policy and market practitioners in the current times of elevated EPU levels due to the Coronavirus outbreak, with rallying policy and macro-financial risks that could drive the contagion of a global turmoil in asset markets. Finally, there is ample room for future research to further explore the macro-determinants of correlation dynamics by concentrating on country-specific markets and macrodrivers in order to reveal the fundamental economic linkages behind cross-asset financial correlations in a multi-country context.

\section{References}

[1] Aastveit, K.A., Natvik, G.J., Sola, S., 2017. Economic uncertainty and the influence of monetary policy. Journal of International Money and Finance 76, 50-67. 
[2] Akay, O., Senyuz, Z., Yoldas, E., 2013. Hedge fund contagion and risk-adjusted returns: A Markovswitching dynamic factor approach. Journal of Empirical Finance 22, 16-29.

[3] Alessandri, P., Mumtaz, H., 2019. Financial regimes and uncertainty shocks. Journal of Monetary Economics 101, 31-46.

[4] Aloui, R., Gupta, R., Miller, S.M., 2016. Uncertainty and crude oil returns. Energy Economics 55, $92-100$.

[5] Andreasson, P., Bekiros, S., Nguyen, D.K., Uddin, G.S., 2016. Impact of speculation and economic uncertainty on commodity markets. International Review of Financial Analysis 43, 115-127.

[6] Antonakakis, N., Chatziantoniou, I., Filis, G., 2013. Dynamic co-movements of stock market returns, implied volatility and policy uncertainty. Economics Letters 120, 87-92.

[7] Antonakakis, N., Chatziantoniou, I., Filis, G., 2014. Dynamic spillovers of oil price shocks and economic policy uncertainty. Energy Economics 44, 433-447.

[8] Aruoba, S.B., Diebold, F.X., Scotti, C., 2009. Real-time measurement of business conditions. Journal of Business and Economic Statistics 27, 417-427.

[9] Bai, J., Perron, P., 1998. Estimating and testing linear models with multiple structural changes. Econometrica 66, 47-78.

[10] Bai, J., Perron, P., 2003a. Computation and analysis of multiple structural change models. Journal of Applied Econometrics 18, 1-22.

[11] Bai, J., Perron, P., 2003b. Critical values for multiple structural change tests. Econometrics Journal $6,72-78$.

[12] Bakas, D., Triantafyllou, A., 2019. Volatility forecasting in commodity markets using macro uncertainty. Energy Economics 81, 79-94.

[13] Baker, S.R., Bloom, N., Davis, S.J., 2016. Measuring economic policy uncertainty. The Quarterly Journal of Economics 131, 1593-1636.

[14] Balli, F., Uddin, G.S., Mudassar, H., Yoon, S.M., 2017. Cross-country determinants of economic policy uncertainty spillovers. Economics Letters 156, 179-183.

[15] Batten, J.A., Kinateder, H., Szilagyi, P.G., Wagner, N.F., 2019. Hedging stocks with oil. Energy Economics, forthcoming. 
[16] Bauwens, L., Laurent, S., Rombouts, J.V.K., 2006. Multivariate GARCH models: A survey. Journal of Applied Econometrics 21, 79-109.

[17] Behmiri, N.B., Manera, M., Nicolini, M., 2019. Understanding dynamic conditional correlations between oil, natural gas and non-energy commodity futures markets. Energy Journal 40, 55-76.

[18] Bekaert, G., Hoerova, M., Lo Duca, M., 2013. Risk, uncertainty and monetary policy. Journal of Monetary Economics 60, 771-788.

[19] Ben-David, I., Fermand, E., Kuhnen, C.M., Li, G., 2018. Expectations uncertainty and household economic behavior. National Bureau of Economic Research, No. w25336.

[20] Benamar, H., Foucault, T., Vega, C., 2018. Demand for information, macroeconomic uncertainty, and the response of US treasury securities to news. HEC Paris Research Paper No. FIN-2018-1263.

[21] Beneki, C., Koulis, A., Kyriazis, N.A., Papadamou, S., 2019. Investigating volatility transmission and hedging properties between Bitcoin and Ethereum. Research in International Business and Finance $48,219-227$.

[22] Bernal, O., Gnabo, J.Y., Guilmin, G., 2016. Economic policy uncertainty and risk spillovers in the Eurozone. Journal of International Money and Finance 65, 24-45.

[23] Bernanke, B.S., 1983. Irreversibility, uncertainty, and cyclical investment. The Quarterly Journal of Economics 98, 85-106.

[24] Bloom, N., 2009. The impact of uncertainty shocks. Econometrica 77, 623-685.

[25] Bloom, N., 2014. Fluctuations in uncertainty. The Journal of Economic Perspectives 28, 153-175.

[26] Bollerslev, T., 1986. Generalized autoregressive conditional heteroskedasticity. Journal of econometrics $31,307-327$.

[27] Bollerslev, T., 1990. Modelling the coherence in short-run nominal exchange rates: A multivariate generalized ARCH model. Review of Economics and Statistics 72, 498-505.

[28] Bordo, M.D., Duca, J.V., Koch, C., 2016. Economic policy uncertainty and the credit channel: Aggregate and bank level US evidence over several decades. Journal of Financial Stability 26, 90106.

[29] Boumparis, P., Milas, C., Panagiotidis, T., 2017. Economic policy uncertainty and sovereign credit rating decisions: Panel quantile evidence for the Eurozone. Journal of International Money and Finance 79, 39-71. 
[30] Brenner, M., Pasquariello, P., Subrahmanyam, M., 2009. On the volatility and comovement of US financial markets around macroeconomic news announcements. Journal of Financial and Quantitative Analysis 44, 1265-1289.

[31] Brogaard, D., Detzel, A., 2015. The asset-pricing implications of government economic policy uncertainty. Management Science 61, 3-18.

[32] Caggiano, G., Castelnuovo, E., Figueres, J.M., 2017. Economic policy uncertainty and unemployment in the United States: A nonlinear approach. Economics Letters 151, 31-34.

[33] Caldara, D., Iacoviello, M. 2018. Measuring geopolitical risk. Board of Governors of the Federal Reserve Board working paper.

[34] Caliendo, F.N., Guo, N.L., Smith, J.M., 2018. Policy uncertainty and bank bailouts. Journal of Financial Markets 39, 111-125.

[35] Caporale, G.M., Spagnolo, F., Spagnolo, N., 2018. Macro news and bond yield spreads in the euro area. The European Journal of Finance 24, 114-134.

[36] Cappiello, L., Engle, R.F., Sheppard, K., 2006. Asymmetric dynamics in the correlations of global equity and bond returns. Journal of Financial Econometrics 4, 537-572.

[37] Carriero, A., Clark, T.E., Marcellino, M., 2018. Measuring uncertainty and its impact on the economy. The Review of Economics and Statistics 100, 799-815.

[38] Case, B., Yang, Y., Yildirim, Y., 2012. Dynamic correlations among asset classes: REIT and stock returns. The Journal of Real Estate Finance and Economics 44, 298-318.

[39] Castelnuovo, E., Tran, T.D., 2017. Google it up! A Google trends-based uncertainty index for the United States and Australia. Economics Letters 161, 149-153.

[40] Cho, D., Han, H., Lee, N.K., 2018. Carry trades and endogenous regime switches in exchange rate volatility. Journal of International Financial Markets, Institutions and Money 58, 255-268.

[41] Chong, J., Krystalogianni, A., Stevenson, S., 2012. Dynamic correlations between REIT sub-sectors and the implications for diversification. Applied Financial Economics 22, 1089-1109.

[42] Christou, C., Gupta, R., Hassapis, C., 2017. Does economic policy uncertainty forecast real housing returns in a panel of OECD countries? A bayesian approach. The Quarterly Review of Economics and Finance 65, 50-60. 
[43] Colacito, R., Engle, R. F., Ghysels, E., 2011. A component model for dynamic correlations. Journal of Econometrics 164, 45-59.

[44] Colombo, V., 2013. Economic policy uncertainty in the US: Does it matter for the Euro area? Economics Letters 121, 39-42.

[45] Connolly, R., Dubofsky, D., Stivers, C., 2018. Macroeconomic uncertainty and the distant forwardrate slope. Journal of Empirical Finance 48, 140-161.

[46] Creti, A., Joëts, M., Mignon, V., 2013. On the links between stock and commodity markets' volatility. Energy Economics 37, 16-28.

[47] Dakhlaoui, I., Aloui, C., 2016. The interactive relationship between the US economic policy uncertainty and BRIC stock markets. International Economics 146, 141-157.

[48] Diebold, F.X., Yilmaz, K., 2009. Measuring financial asset return and volatility spillovers, with application to global equity markets. Economic Journal 119, 158-171.

[49] Dixit, A.K, Pindyck, R.S., 1994. Investment under uncertainty. Princeton, NJ: Princeton University Press.

[50] Engle, R.F., 2002. Dynamic conditional correlation: A simple class of multivariate generalized autoregressive conditional heteroskedasticity models. Journal of Business and Economic Statistics 20, 339-350.

[51] Engle, R.F., Kelly, B.T., 2012. Dynamic equicorrelation. Journal of Business and Economic Statistics $30,212-228$.

[52] Estrella, A., Hardouvelis, G.A., 1991. The term structure as a predictor of real economic activity. The Journal of Finance 46, 555-576.

[53] Fang, L., Bouri, E., Gupta, R., Roubaud, D., 2019. Does global economic uncertainty matter for the volatility and hedging effectiveness of Bitcoin? International Review of Financial Analysis 61, 29-36.

[54] Fang, L., Chen, B., Yu, H., Qian, Y., 2018a. The importance of global economic policy uncertainty in predicting gold futures market volatility: A GARCH-MIDAS approach. Journal of Futures Markets $38,413-422$.

[55] Fang, L., Chen, B., Yu, H., Xiong, C., 2018b. The effect of economic policy uncertainty on the long-run correlation between crude oil and the US stock markets. Finance Research Letters 24, 56-63. 
[56] Forbes, J. K., Rigobon, R., 2002. No contagion, only interdependence: Measuring stock market comovements. The Journal of Finance 57, 2223-2261.

[57] Fountas, S., Karanasos, M., 2007. Inflation, output growth, and nominal and real uncertainty: Empirical evidence for the G7. Journal of International Money and Finance 26, 229-250.

[58] Gabauer, D., Gupta, R., 2018. On the transmission mechanism of country-specific and international economic uncertainty spillovers: Evidence from a TVP-VAR connectedness decomposition approach. Economics Letters 171, 63-71.

[59] Glosten, L. R., Jagannathan, R., Runkle, D. E., 1993. On the relation between the expected value and the volatility of nominal excess return on stocks. Journal of Finance 48, 1779-1801.

[60] Gulen, H., Ion, M., 2015. Policy uncertainty and corporate investment. The Review of Financial Studies 29, 523-564.

[61] Huang, J.Z., Zhong, Z.K., 2013. Time variation in diversification benefits of commodity, REITs, and TIPS. The Journal of Real Estate Finance and Economics 46, 152-192.

[62] Jo, S., Sekkel, R., 2019. Macroeconomic uncertainty through the lens of professional forecasters. Journal of Business and Economic Statistics 37, 436-446.

[63] Jones, P.M., Olson, E., 2013. The time-varying correlation between uncertainty, output, and inflation: Evidence from a DCC-GARCH model. Economics Letters 118, 33-37.

[64] Jurado, K., Ludvigson, S. D., Ng, S. 2015. Measuring uncertainty. American Economic Review 105, $1177-1216$.

[65] Kang, W., de Gracia, F.P., Ratti, R.A., 2017a. Oil price shocks, policy uncertainty, and stock returns of oil and gas corporations. Journal of International Money and Finance 70, 344-359.

[66] Kang, S.H., McIver, R., Yoon, S.M., 2017b. Dynamic spillover effects among crude oil, precious metal, and agricultural commodity futures markets. Energy Economics 62, 19-32.

[67] Karaman, K.K., Yildirim-Karaman, S., 2019. How does financial development alter the impact of uncertainty? Journal of Banking and Finance 102, 33-42.

[68] Karanasos, M., Yfanti, S., 2020. On the macro-drivers of realized volatility: the destabilizing impact of UK policy uncertainty across Europe. The European Journal of Finance, forthcoming. 
[69] Karanasos, M., Yfanti, S., Karoglou, M., 2016. Multivariate FIAPARCH modelling of financial markets with dynamic correlations in times of crisis. International Review of Financial Analysis 45, $332-349$.

[70] Karanasos, M., Menla Ali, F., Margaronis, Z., Nath, R., 2018. Modelling time varying volatility spillovers and conditional correlations across commodity metal futures. International Review of Financial Analysis 57, 246-256.

[71] Kelly, B., Pastor, L., Veronesi, P., 2016. The price of political uncertainty: Theory and evidence from the option market. The Journal of Finance 71, 2417-2480.

[72] Kido, Y., 2016. On the link between the US economic policy uncertainty and exchange rates. Economics Letters 144, 49-52.

[73] Klößner, S., Sekkel, R., 2014. International spillovers of policy uncertainty. Economics Letters 124, 508-512.

[74] Knight, F.H., 1921. Risk, uncertainty, and profit. Boston, MA: Hart, Schaffner \& Marx; Houghton Mifflin Company.

[75] Larsen, V.H., Thorsrud, L.A., 2018. The value of news for economic developments. Journal of Econometrics 210, 203-218.

[76] Li, X.M., Zhang, B., Gao, R., 2015. Economic policy uncertainty shocks and stock-bond correlations: Evidence from the US market. Economics Letters 132, 91-96.

[77] Liow, K.H., 2012. Co-movements and correlations across Asian securitized real estate and stock markets. Real Estate Economics 40, 97-129.

[78] Liow, K.H., Zhou, X., Ye, Q., 2015. Correlation dynamics and determinants in international securitized real estate markets. Real Estate Economics 43, 537-585.

[79] Lucey, B.M., Li, S., 2015. What precious metals act as safe havens, and when? Some US evidence.Applied Economics Letters 22, 35-45.

[80] Mumtaz, H., Theodoridis, K., 2018. The changing transmission of uncertainty shocks in the U.S. Journal of Business and Economic Statistics 36, 239-252.

[81] Nagar, V., Schoenfeld, J., Wellman, L., 2018. The effect of economic policy uncertainty on investor information asymmetry and management disclosures. Journal of Accounting and Economics 67, 3657. 
[82] Pan, Z., Wang, Y., Liu, L., 2016. The relationships between petroleum and stock returns: An asymmetric dynamic equi-correlation approach. Energy Economics 56, 453-463.

[83] Pappas, V., Ingham, H., Izzeldin, M., Steele, G., 2016. Will the crisis "tear us apart"? Evidence from the EU. International Review of Financial Analysis 46, 346-360.

[84] Pastor, L., Veronesi, P., 2012. Uncertainty about government policy and stock prices. The Journal of Finance 67, 1219-1264.

[85] Pastor, L., Veronesi, P., 2013. Political uncertainty and risk premia. Journal of Financial Economics $110,520-545$.

[86] Pham, A.V., 2019. Political risk and cost of equity: The mediating role of political connections. Journal of Corporate Finance 56, 64-87.

[87] Rossi, B., Sekhposyan, T., 2015. Uncertainty indices based on nowcast and forecast error distributions. American Economic Review 105, 650-655.

[88] Scheffel, E.M. 2016. Accounting for the political uncertainty factor. Journal of Applied Econometrics 31, 1048-1064.

[89] Scotti, C., 2016. Surprise and uncertainty indexes: Real-time aggregation of real-activity macrosurprises. Journal of Monetary Economics 82, 1-19.

[90] Silvennoinen, A., Teräsvirta, T., 2009. Multivariate GARCH models. In Andersen, T.G., Davis, R.A., Kreiß, J.-P., Mikosch, T. (Eds.), Handbook of Financial Time Series (pp. 201-228). Berlin: Springer-Verlag.

[91] Silvennoinen, A., Thorp, S., 2013. Financialization, crisis and commodity correlation dynamics. Journal of International Financial Markets, Institutions and Money 24, 42-65.

[92] Skintzi, V.D., 2019. Determinants of stock-bond market comovement in the Eurozone under model uncertainty. International Review of Financial Analysis 61, 20-28.

[93] Tarassow, A., 2019. Forecasting US money growth using economic uncertainty measures and regularisation techniques. International Journal of Forecasting 35, 443-457.

[94] Vlastakis, N., Markellos, R. N., 2012. Information demand and stock market volatility. Journal of Banking and Finance 36, 1808-1821.

[95] Wisniewski, T.P., Lambe, B.J., 2015. Does economic policy uncertainty drive CDS spreads? International Review of Financial Analysis 42, 447-458. 
[96] Yang, J., Zhou, Y., Leung, W.K., 2012. Asymmetric correlation and volatility dynamics among stock, bond, and securitized real estate markets. The Journal of Real Estate Finance and Economics $45,491-521$.

[97] Yusupova, A., Pavlidis, E.G., Paya, I., Peel, D.A., 2019. UK Housing Price Uncertainty Index (HPU), UK Housing Observatory, Dept. of Economics, Lancaster University Management School.

[98] Zhong, W., Lin, Y., Gao, D., Yang, H., 2019. Does politician turnover affect foreign subsidiary performance? Evidence in China. Journal of International Business Studies, 50, 1184-1212. 